Originalveröffentlichung in: Oesterle, Günter; Roeck, Bernd; Tauber, Christine

(Hrsgg.): Italien in Aneignung und Widerspruch, Tübingen 1996, S. 62-92 (Reihe

der Villa Vigoni ; 10)

Christine Tauber (Bonn)

\title{
Der lange Schatten aus Weimar - Goethe und Burckhardts Italienbild
}

\section{I.1. Goethes »Italienische Reise« als Muster der Italienaneignung}

Zweimal hat sich Heinrich Heine über Goethes »Italienische Reise « geäußert: Einmal 1826, in der "Nordsee ${ }^{1}{ }^{1}$ hier noch eher in bewunderndem Ton, ironischdistanzierter dann in seiner »Reise von München nach Genua» von 1830:

»Kennst du das Land, wo die Zitronen blühen? «ennst du das Lied? Ganz Italien ist darin geschildert, aber mit den seufzenden Farben der Sehnsucht. In der »Italienischen Reise« hat es Goethe etwas ausführlicher besungen, und wo er malt, hat er das Original immer vor Augen, und man kann sich auf die Treue der Umrisse und der Farbengebung ganz verlassen. Ich finde es daher bequem, hier ein für allemal auf Goethes »Italienische Reise« hinzudeuten (...). Ich habe schon früherhin über jenes Buch gesprochen, ehe ich den Stoff, den es behandelt, gekannt habe, und ich finde jetzt mein ahnendes Urteil vollauf bestätigt. Wir schauen nämlich darin überall tatsächliche Auffassung und Ruhe der Natur. Goethe hält ihr den Spiegel vor, oder besser gesagt, er ist selbst der Spiegel der Natur. Die Natur wollte wissen, wie sie aussieht, und sie erschuf Goethe. Sogar die Gedanken, die Intentionen der Natur vermag er uns wiederzuspiegeln, und es ist einem hitzigen Goethianer, zumal in den Hundstagen, nicht zu verargen, wenn er über die Identität der Spiegelbilder mit den Objekten selbst so sehr erstaunt, daß er dem Spiegel sogar Schöpfungskraft, die Kraft, ähnliche Objekte zu erschaffen, zutraut. Ein Herr Eckermann hat mal ein Buch über Goethe geschrieben, worin er ganz ernsthaft versichert: hätte der liebe Gott bei der Erschaffung der Welt zu Goethe gesagt: »Lieber Goethe, ich bin jetzt gottlob fertig, ich habe jetzt alles erschaffen, bis auf die Vögel und die Bäume, und du tätest mir eine Liebe, wenn du statt meiner diese Bagatellen noch erschaffen wolltest « - so würde Goethe, ebensogut wie der liebe Gott, diese Tiere und Gewächse ganz im Geiste der übrigen Schöpfung, nämlich die Vögel mit Federn und die Bäume grün, erschaffen haben. ${ }^{2}$

Doch Goethes demiurgische Fähigkeiten gingen noch weiter: Er hat den Deutschen ein Italienbild erschaffen, um das ihn nicht nur die Natur beneidet. Im folgenden soll der Frage nachgegangen werden, wieso die bildungsbürgerliche Epiphanie Italiens im 19. und 20. Jahrhundert fast ausschließlich durch Goethes »klare Griechenaugen « (Heine) erfolgte, wie die »Italienische Reise « zum Hauptmuster der Italienaneignung avancieren konnte und die nachfolgenden Reisenden

${ }^{1}$ Heinrich Heine, Die Nordsee. Dritte Abtheilung, in: id., Säkularausgabe. Werke. Briefwechsel. Lebenszeugnisse, hrsg. v. den Nationalen Forschungs- und Gedenkstätten der klassischen deutschen Literatur in Weimar u. dem CNRS in Paris, Bd. 5: Reisebilder I, Berlin/Paris 1970, 66.

${ }^{2}$ Heinrich Heine, Reise von München nach Genua, in: id., Säkularausgabe, op. cit., Bd. 6: Reisebilder II, Berlin/Paris 1986, 53f. 
sich geradezu einem Zwang des Hochgestimmtseins und Gleichgestimmtseins mit dem "Cicerone aus Weimar « unterwarfen, so daß der Bildungsbürger in Italien »streckenweise anhand von Goethes Reisebuch (...) kommuniziert(e) ${ }^{3}{ }^{3}$ Goethe war sich seiner Mission für die nachfolgenden Generationen von Reisenden sehr wohl bewußt, als er an exponierter Stelle, am Ende des Zweiten Teils der »Italienischen Reise«, schrieb:

Überhaupt, wenn jeder Mensch nur als ein Supplement aller übrigen zu betrachten ist, und am nützlichsten und liebenswürdigsten erscheint wenn er sich als einen solchen gibt; so $\mathrm{muß}$ dieses vorzüglich von Reiseberichten und Reisenden gültig sein. (IR 422$)^{4}$

Und noch unverhohlener selbstgewiß heißt es am 13. April 1787: „Bin ich doch nur ein Vorfahre von künftigen andern, im Leben wie auf der Reise! « (IR 312) ${ }^{5}$

Eine wichtige Rolle bei der Beantwortung der Frage nach dem Kanonischwerden der "Italienischen Reise " spielt die Tatsache, daß es sich bei dem 1816 bzw. 1829 (Zweiter Römischer Aufenthalt) veröffentlichten Text mitnichten um die Dokumentation eines frischen und authentischen Erlebens handelt, sondern um die Redaktion eines Textes, die Goethe rund dreißig Jahre nach seiner Reise vornahm. Die "Italienische Reise " ist ein Text des alten Goethe, der sich in klassischen Posen gefiel und der seinem Aufenthalt in Italien im nachhinein einen ganz bestimmten Ort in seiner eigenen künstlerischen und charakterlichen Entwicklung zuweisen wollte. Die Materialien der Italienreise wurden geglättet und vereinheitlicht, die Reise selbst zu einer Epoche des Übergangs zur Klassik stilisiert, zu einer Bildungsreise ins »klassische Land «. Die Italienreise bekommt einen notwendigen und festen Platz in der Entwicklung und Bildung ihres Verfassers zugewiesen. Der Reisende Goethe wird mit allen Tugenden ausgestattet, die einem Klassiker angemessen sind und die gerade im Bildungsbürgertum des 19. Jahrhunderts Hochkonjunktur haben sollten: Ruhe, Ausgeglichenheit, charakterliche Festigkeit, maßvolles Verhalten, ${ }^{6}$ Distanziertheit zu aller potentiellen Irritation durch Natur und Kunst, Fleiß und Beflissenheit im Betrachten des Schönen und

${ }^{3}$ Vgl. Ferdinand van Ingen, Goethes Italienische Reise: Ein fragwürdiges Modell, in: Italienische Reise. Reisen nach Italien, hrsg. v. Italo Michele Battafarano, Trient 1988, $177-$ 229, hier 185; man vergleiche zur Wirkungsklassizität der »Italienischen Reise« z. B. Publikationen wie: Mit Goethe in Italien. Tagebuch und Briefe des Dichters in Italien. Für deutsche Italienfahrer herausgegeben von Julius Vogel, Berlin 1908; die wegweisende Funktion, die auf literarischer Seite die »Italienische Reise « hatte, wurde in der Guidenliteratur in der zweiten Hälfte des 19. Jahrhunderts von Baedekers Reisebüchern übernommen.

${ }^{4}$ Die "Italienische Reise« (= IR) wird im folgenden nach der Münchner Ausgabe, Bd. 15, hrsg. v. Andreas Beyer u. Norbert Miller, München 1992 zitiert.

${ }^{5}$ Vgl. auch IR 588, wo der Römische Carneval als ein Fest beschrieben wird, »das sich jährlich wiederholt, und das von manchem, mit diesem Buche in der Hand, künftig betrachtet werden wird.«

${ }^{6}$ Ernst Osterkamp, Im Buchstabenbilde. Studien zum Verfahren Goethescher Bildbeschreibungen, Stuttgart 1991, 340 spricht von »Goethes Ästhetik des Maßes « und verdeutlicht dies anhand von Goethes Ruysdael-Beschreibungen, in dessen Bildern Goethe 
Würdigen, das Verfügen über einen festen, nachvollziehbaren Urteilskanon im Umgang mit den Kunstwerken, die dadurch fixierbar, feststellbar werden und vor allem die Fähigkeit, sich das Fremde anzueignen. Goethes Reisemaxime lautet: "Ich lebe sehr diät und halte mich ruhig, damit die Gegenstände keine erhöhte Seele finden, sondern die Seele erhöhen.« (TB 80). ${ }^{7}$ Die wenigen tatsächlichen Kunstbeschreibungen in der »Italienischen Reise « bleiben hinlänglich klassizistisch-formal und somit unspezifisch, so daß eine Adaptation durch die Nachreisenden leicht möglich wurde. ${ }^{8}$ Gleichzeitig werden die Werke der großen Künstler einerseits durch eine Art »Veredelungsprozeß« in eine hinreichende Distanz zum Betrachter gebracht, ${ }^{9}$ andererseits ins Geheimnisvoll-Unerreichbare entrückt. Sie sind göttliche Schöpfung, über die man nicht sprechen kann und deren tatsächlichem Wert man durch Beschreibung nicht gerecht wird, deren Ganzheit und Geschlossenheit man durch eine sezierende Analyse zerstören würde. In verzücktem Schauen ${ }^{10}$ verharrt der Betrachter vor dem Kunstwerk: „Die Kunst ist deshalb da, daß man sie sehe, nicht davon spreche, als höchstens in ihrer Gegenwart.« (IR 453). ${ }^{11}$ Will er den Kanon des Großen und Würdigen nicht zerstören, muß er sich jeglichen Urteils enthalten und auf der Nichtkommunizierbarkeit der Idee des Kunstschönen bestehen: "Ich halte die Augen nur immer offen, und drücke mir die Gegenstände recht ein. Urteilen möchte ich gar nicht, wenn es nur möglich wäre.« (IR 141) Goethes Bemerkungen in der Sixtinischen Kapelle klingen wie die Lebensmaxime des bildungsbeflissenen deutschen Reisenden, der in Italien ehrfurchtsvoll-philiströs dem Itinerar der Baedeker-Sterne folgt: ${ }^{12}$

durchweg die Beruhigung und Bändigung der Natur und ihrer Gewalten durch den schaffenden und tätigen Menschen betont.

${ }^{7}$ Das » Tagebuch der Italienischen Reise für Frau von Stein 1786« $(=$ TB) wird im folgenden zitiert nach der Münchner Ausgabe, Bd. 3.1, hrsg. v. Norbert Miller u. Hartmut Reinhardt, München 1990.

${ }^{8}$ Vgl. Andreas Beyer, Bestimmung und Selbstbestimmung Goethes in der »Italienischen Reise«, in: Johann Wolfgang Goethe, Italienische Reise, op. cit., 657-668, v. a. 666; vgl. auch Wilfried Barner, »Altertum, Überlieferung, Natur. Über Klassizität und autobiographische Konstruktion in Goethes >Italienischer Reise «, in: GJb 105 (1988), 68; 92, der die Wirkung der »Italienischen Reise « als »epochemachenden Individualmythos « unter anderem durch das Fehlen eines durchgängigen Erzählers und durch die Diskontinuität in der Abfolge des Erzählten zu erklären versucht.

${ }^{9}$ Vgl. Marianello Marianelli, »Die Idee der Entwicklung im Spiegel von Goethes >Italienischer Reise «, in: GJb 99 (1982), 117-132, hier 129.

${ }^{10}$ Bei Goethe trägt die Kunstbetrachtung zum Teil Züge einer quasi-mystischen Schau; vgl. hierzu v. a. die Anspielung auf Böhmes Erweckungserlebnis in der "Italienischen Reise«, IR 103.

${ }^{11}$ Vgl. auch Goethe, Philostrats Gemälde, in: BA 20, 213f: "Da jedoch weder die wohldurchdachte Komposition noch die Anmut der Einzelheiten, weniger das Glück, womit Licht und Schatten, von Farbe begleitet, einander entgegengesetzt sind, sich keineswegs durch Worte aussprechen lassen, so wünschen wir gedachtes Blatt den Kunstfreunden gelegentlich nachgebildet mitzuteilen (...).*

${ }^{12}$ Vgl. auch Nietzsches sehr treffende Beschreibung goethescher Gestalten in der Dritten 
Wir ergetzten uns als genießende Menschen, an der Größe und der Pracht, ohne durch allzueklen und zu verständigen Geschmack uns diesmal irre machen zu lassen, und unterdrückten jedes schärfere Urteil. Wir erfreuten uns des Erfreulichen. (IR 167)

Hierbei handelt es sich nicht, wie man vermuten könnte, um eine verdeckte Michelangelo-Kritik, die die erschreckenden und dämonischen Züge des Malers ungenannt lassen möchte, um nicht in der Einstimmung gestört zu werden. Goethes Verhältnis zu Michelangelo ist nämlich längst nicht so negativ wie das der Goethe-Nachfolger im 19. Jahrhundert (v.a. das Burckhardts). Zwar spürt man auch bei Goethe ein gewisses Unbehagen über die Gewaltsamkeit michelangelesker Bildungen und Figuren, gleichzeitig würdigt er ihn aber auch als Meister der Darstellung des menschlichen Körpers. ${ }^{13}$ Auch den Streitigkeiten in der deutschen Künstlerkolonie über den Vorrang Michelangelos oder Raffaels begegnet Goethe mit Seelenruhe:

Mich konnten dergleichen Streitigkeiten nicht irre machen, da ich sie auf sich beruhen ließ und mich mit unmittelbarer Betrachtung alles Werten und Würdigen beschäftigte. (IR 473)

Die in der »Italienischen Reise " geradezu topisch immer wieder beklagte NichtKommunizierbarkeit von Kunsteindrücken ist wohl auch zurückzuführen auf die nicht nur in Weimar im 18. Jahrhundert praktizierte Form des Austauschs im geselligen Freundschaftsgespräch. Wird ein Mitglied dieses Freundeskreises der gleichgestimmten Gesprächsrunde durch die Reise entrückt, so wird ihm die adäquate Mitteilung seiner neuen Erfahrungen, die im Extremfall sogar den Konsens der geselligen Runde sprengen könnten, unmöglich. Geselligkeit war unabdingbare Voraussetzung, um die Einbildungskraft der kunstiiebhabenden Diskutanten in Gang zu setzen - und dieses Defizit können Briefe allein nicht kompensieren:

Lebt wohl und vergnügt, und wenn es Euch weh werden will; so fühlt nur recht daß Ihr beisammen seid und was Ihr einander seid, indes ich durch eigenen Willen exiliert, mit

Unzeitgemäßen Betrachtung, in: id., Kritische Studienausgabe, hrsg. v. Giorgio Colli u. Mazzino Montinari, Bd. I, München/Berlin/New York ${ }^{2} 1988,369 f f .: ~ » D e r$ Mensch Goethe's ist (...) sogar das Correctiv und Quietiv gerade jener gefährlichen Aufregungen, denen der Mensch Rousseau's preisgegeben ist. (...) der Mensch Goethe's (...) hasst jedes Gewaltsame, jeden Sprung - das heisst aber: jede That; und so wird aus dem Weltbefreier Faust gleichsam nur ein Weltreisender. (...) Wenn der Deutsche aufhört, Faust zu sein, ist keine Gefahr grösser als die, dass er ein Philister werde und dem Teufel verfalle (...). Der Goethesche Mensch ist eine erhaltende und verträgliche Kraft - aber unter der Gefahr, wie gesagt, dass er zum Philister entarten kann (...).«; vgl. Italo Michele Battafarano, Genese und Metamorphose des Italienbildes in der deutschen Literatur der Neuzeit, in: Italienische Reise. Reisen in Italien, op. cit., 13-101, hier 13: „Falsch reist allemal jener Deutsche [nach Italien] ein, für den - zumindest seit Goethes Reise - die Italienreise zur Pflicht gerann, zu dessen Reisegepäck ein Konglomerat von Äußerungen deutscher Kulturgrößen gehört, die es vor Ort zu verifizieren gilt. «

${ }^{13}$ Vgl. hierzu Herbert von Einem, »Goethe und Michelangelo«, in: GJb 92 (1975), 165-194. 
Vorsatz irrend, zweckmäßig unklug, überall fremd und überall zu Hause, mein Leben mehr laufen lasse als führe und auf alle Fälle nicht weiß wo es hinaus will. (IR 497)

Um den Daheimgebliebenen die Augen wenigstens einen Spalt weit für das von ihm Gesehene zu öffnen, plante Goethe eine illustrierte Ausgabe der »Italienischen Reise ${ }^{14}{ }^{14}$

Ein probates Mittel der Aneignung von bisher Unbekanntem ist für Goethe dessen Einordnung und Klassifizierung: Dem Neuen wird eine Schublade im Schrank des schon Bekannten zugewiesen, ${ }^{15}$ in allem Individuellen wird das allgemeine Prinzip erkannt, die potentiell irritierende Anschauung wird auf einen Begriff gebracht (IR 290). Indem Goethe seinen »morphologischen Blick « ${ }^{16}$ auf alles Neue richtet, unterwirft er es seiner Gestalterkenntnis, blickt nur auf die allgemeine Form, die sich in jedem Einzelfall neu manifestiert, subordiniert es einem Muster und glaubt so, die »Sicherheit und Gewißheit [zu haben], die Dinge für das zu nehmen was sie sind ${ }^{17}{ }^{17}$ Und so entpuppt sich der Topos des »das Auge licht sein lassens « (IR 157) ebenfalls als bewußte Verschleierung: Denn nicht die hier suggerierte unvermittelte, direkte und ungefilterte Anschauung wird praktiziert, sondern Goethe taucht die Gegenstände in das Scheinwerferlicht seines Blicks, der durch den Raster seiner persönlichen Kunst- und Naturauffassung hindurch nur sehr bestimmte Dinge fokussiert und andere im Dunkeln beläßt. ${ }^{18}$ Vor allem das Widerwärtige, Unbequeme und Unerwartete wird eliminiert:

${ }^{14}$ Ernst Osterkamp, op. cit., 319; zu Goethes Klagen über den fehlenden Freundeskreis vgl. u. a. IR 479: »Könnte ich meinen Geliebten nur etwas von meinem Genuß und meiner Empfindung mitteilen!«; IR 325: »(...) allein als ich zu Hause meine Rechnung machte, meine Kasse und Papiere überschlug, sah ich wohl daß in einem Lande, wo durch Mangel von Kommunikation die Entfernung gleichsam ins Unendliche wächst, ich mich selbst in Verlegenheit setzen würde (...) «; Goethes Briefe, Hamburger Ausgabe in vier Bänden, Bd. II, Hamburg ${ }^{2} 1968$, Nr. 420, 15; Nr. 439, 47; Nr. 457, 75: »Es ist eine Materie von der sich kaum reden, geschweige schreiben läßt, sie sei also zu künftigen Unterhaltungen aufgespart.«

${ }^{15}$ Vgl. hierzu Norbert Miller, Spiegelungen des Sizilianischen Abenteuers, Stuttgart 1994 (Abhandlungen der Akademie der Wissenschaften und der Literatur, Mainz). Miller betont hier, »wie sehr sein [Goethes] Kunsturteil vom spontanen Wiedererkennen des innerlich Verwandten abhängig war.«; op. cit., 27.

${ }^{16}$ Ferdinand van Ingen, op. cit., 220; vgl. ibid.: »Die Schulung des Auges durch Betrachtung von Kunstwerken und durch eigene Zeichenversuche ist auf solche Gesetzlichkeit der notwendigen, natürlichen Gestalt gerichtet. Das denkende Anschauen, das genetisch verfährt, wird auf alle Lebenserscheinungen angewandt und beansprucht innere Wahrheit, Objektivität.«

${ }^{17}$ Goethe in dem Brief an die Herzogin Louise vom 23. Dezember 1786, in: Goethes Briefe, op. cit., Nr. 430, 30.

${ }^{18}$ Noch Rudolf Borchardt sitzt der Goetheschen Selbststilisierung auf, wenn er schreibt, Goethe habe die whistorische, ethnische und geistige Beschaffenheit [der Italiener] mit der Vernunft des Liebenden bis in letzte Einzelheiten « durchdrungen, erklärt und verteidigt; Rudolf Borchardt, Goethe, in: id., L'Italia e la poesia tedescha, Frankfurt a. M. 1988,84 . 
Der Genuß auf einer Reise ist wenn man ihn rein haben will, ein abstrakter Genuß, ich muß die Unbequemlichkeiten, Widerwärtigkeiten, das was mit mir nicht stimmt, was ich nicht erwarte, alles muß ich bei Seite bringen, in dem Kunstwerk nur den Gedanken des Künstlers, die erste Ausführung, das Leben der ersten Zeit da das Werk entstand heraussuchen und es wieder rein in meine Seele bringen, abgeschieden von allem was die Zeit, der alles unterworfen ist und der Wechsel der Dinge darauf gewürkt haben. Dann hab ich einen reinen bleibenden Genuß und um dessentwillen bin ich gereist, nicht um des Augenblicklichen Wohlseins oder Spaßes willen. (TB 82f., 25. 9. 1786)

Charakteristischerweise befällt Goethe später geradezu ein schlechtes Gewissen angesichts der ausschließlich harmonischen Tableaux, die er von Arkadien entwirft, und so nimmt er sich vor: »Für diesmal schließ' ich, und werde das nächste Blatt ganz von Unheil, Mord, Erdbeben und Unglück anfüllen, daß doch auch Schatten in meine Gemälde komme.« (IR 173). Natürlich bleibt es bei diesem heroischen Vorsatz, und Italienkritiker wie Archenholtz werden weiterhin mit stiller Verachtung gestraft (IR 172).

Auch beim Zeichnen »schematisiert« Goethe - dieser Begriff spielt wahrscheinlich auf das sogenannte Rubrikenschema an, ${ }^{19}$ das Heinrich Meyer zusammen mit Goethe in Anlehnung an Mengs zur Beschreibung von Kunstwerken entwarf und das die klassischen Rubriken der Bildbewertung (Erfindung/Invenzione, Komposition, Ausdruck, Zeichnung, Pinselführung, Kolorit, Beleuchtung und Draperie) $)^{20}$ enthielt. Generell wird ihm die eigene zeichnerische Produktion zum Mittel der Objektivierung, zugleich der Fixierung der neuen Eindrücke - »Italien wird ihm zu einer Schatzkammer großer Gegenstände, die er sich sinnlich und geistig zueignen möchte ${ }^{21}{ }^{21}$

Ein Blick auf die Metaphorik, die Goethe in der »Italienischen Reise « verwendet, um sein Verhältnis zu Italien und die Strategien seiner Aneignung dieses Landes zu beschreiben, ist äußerst aufschlußreich: Dem Gegenstand wird »seine Eigentümlichkeit « abgewonnen (IR 231), er gehorcht immer demselben "Prinzip» (IR 252; 476), »alles rückt auf Einen Punkt zusammen« (IR 477), so daß Goethe überall dasselbe »Modell«, dasselbe »Gesetz « finden kann, das er mit dem einmal gefundenen "Schlüssel« erschließt (IR 394) und mit seiner »Schraube ohne Ende « (IR 500) bezwingt. Er »erwirbt« sich so sein Bild (IR 275), er »zwingt« (IR 471)

${ }^{19}$ Vgl. zu Goethes Hang zum Schematisieren auch das bekannte »Dilettantismusschema « von 1799 .

${ }^{20}$ Vgl. hierzu Osterkamp, op. cit., 92ff.; vgl. IR 289: »Kniep zeichnete, ich schematisierte, beide mit großem Genuß und nun da wir fröhlich nach Hause kommen fühlen wir beide weder Kräfte noch Mut zu wiederholen und auszuführen. Unsere Entwürfe müssen also für künftige Zeiten liegen bleiben und dieses Blatt gibt Euch bloß ein Zeugnis unseres Unvermögens diese Gegenstände genugsam zu fassen, oder vielmehr unserer AnmaBung, sie in so kurzer Zeit e r o be r n und be he r r s c h e n zu wollen. [Hervorhebungen von mir]«; vgl. auch IR 308 .

${ }^{21}$ Wanda Kampmann, »Die Kunstanschauung Goethes in der ,Italienischen Reise « , in: Italien II, Hft. 7 (1929), 369; vgl. auch Norbert Miller, Der Dichter als Landschaftsmaler, in: Michael Ruetz, Goethes Italienische Reise. »Auch ich in Arkadien«, Stuttgart 1992, 9. 
die Dinge, sich seinen Schemata unterzuordnen. Ist »die Ernte erst niedergemäht«, kann sie zu »Garben« zusammengebunden werden (IR 207), hat der Betrachter sich erst "wie eine Flasche, (...) die man oben offen unter das Wasser stößt « (IR 463) mit Eindrücken angefüllt, so kann er sich einen ewigen, untransformierbaren Thesaurus des »Alten und Bleibenden« (IR 449) anlegen, auf den er in schweren nördlichen Stunden zurückgreifen kann.

Man könnte behaupten, daß Goethe in Italien nur das suchte, was er schon kannte. $^{22}$ So schreibt er bereits am 25 . September 1786 an Frau v. Stein: »Was mich freut ist daß keine von meinen alten Grundideen verrückt und verändert wird, es bestimmt sich nur alles mehr, entwickelt sich und wächst mir entgegen.« (TB 81) Das Italien, das er sucht und findet, ist das edle und einfältig-schöne Italien Winckelmanns, das Italien, dessen klassische Umrißlinie er seinem Auge bei der Betrachtung pittoresker Stiche und Prospekte früh eingeprägt hatte. ${ }^{23}$ Vor allem römische Veduten mit bevorzugt antiken Motiven ${ }^{24}$ heizten seine Sehnsucht nach Italien an - ebenso wie wohl die Erzählungen seines Vaters -, und so wird begreiflich, wieso Goethe gerade in Rom die Beruhigung finden kann (»Nun bin ich hier und ruhig und wie es scheint auf mein ganzes Leben beruhigt «, IR 147), die so viele Künstler vor und nach ihm gerade in dieser Stadt vergeblich suchten, da sie sich von der Übermacht der Zeugnisse der Vergangenheit bedrängt und erdrückt fühlten. ${ }^{25}$ Das Gegenbild zu diesem apollinischen Reisenden, dessen Reisebeschreibung »der Roman einer Selbstdisziplinierung eines Reisenden auf dem Weg zu den Prinzipien klassischer Kunst ${ }^{26}$ zu sein scheint, ist der titanenhafte, dionysi-

${ }^{22}$ Vgl. Ferdinand van Ingen, op. cit., 227: »Italien interessierte Goethe überhaupt nicht, die Menschen blieben ihm fremd, für die soziale Wirklichkeit war er weitgehend blind, das Politische wird nur in einer gelegentlichen Nebenbemerkung gestreift. Stattdessen bietet er ein arkadisches Bild, das Schattenseiten zwar nicht negiert, aber doch durch überwiegende Helligkeit kontrapunktiert und harmonisiert.«; und - weniger polemisch und differenzierter - Italo Michele Battafarano, op. cit., 45: »In Goethes Italienischer Reise wird zwar auch eine Italienreise literarisch transfiguriert und als literarisches Modell ist sie äußerst folgenreich, ihr liegt aber keine Einheit und keine Gleichzeitigkeit von dem in ihr propagierten kulturellen Modell und dem bereisten Land und seinen Bewohnern zugrunde, ja Goethes Reise und Reise-Buch erstreben das zu keiner Zeit.«

${ }^{23}$ Vgl. Norbert Miller, Landschaftsmaler, op. cit., 12; vgl. Goethes Briefe, op. cit., Nr. 423, 18: »Wie wohl mirs ist daß sich so viele Träume und Wünsche meines Lebens auflösen, daß ich nun die Gegenstände in der Natur sehe die ich von Jugend auf in Kupfer sah, und von denen ich den Vater so oft erzählen hörte, kann ich Ihnen nicht ausdrücken.«

${ }^{24}$ Dies ist wohl mit ein Grund dafür, daß Goethe zu Beginn seiner Reise vollkommen auf die Antike fixiert ist und diese selbst in Venedig sucht.

${ }^{25}$ Selbst als er von wungeheuern Mächten hin und her geworfen « wird, vertraut Goethe seiner Fähigkeit der Ruhigstellung: »Auch ich steure, auf einem leidenschaftlich bewegten Meere dem Hafen zu, und halte ich die Glut des Leuchtturms nur scharf im Auge, wenn sie mir auch den Platz zu verändern scheint, so werde ich doch zuletzt am Ufer genesen.« (IR 211). Höhepunkt dieser Selbstberuhigungsstrategien ist Goethes »ruhiges Zählen « in den Pausen der Vesuvausbrüche während der Besteigung desselben, IR 236.

${ }^{26}$ Dieter Breuer, Sinnenlust und Entsagung. Goethes Versuche, Heinses Italiendarstellung zu korrigieren, in: Italienische Reise, Reisen nach Italien, op. cit., 153-175, hier 157. 
sche Wilhelm Heinse, der Rom geradezu mit physischer Gewalt in Besitz nimmt, und für den Italien ein "panerotisches ${ }^{27}$ Land ist. Was Goethe mit dem ruhigbefriedigten Schritt durch die Porta del Popolo gelingt, wo er sich auch sogleich »gewiß« ist, »Rom zu haben « (IR 146), dafür bedarf es bei Heinse erst eines nächtlichen Eroberungssturmes über die Hügel der Ewigen Stadt. ${ }^{28}$

Tatsächlich beunruhigt ist Goethe erst in Neapel, als mit dem Angebot des Fürsten v. Waldeck plötzlich das wirklich Neue und Fremde, die »terra incognita« Griechenland, aufscheint:

Der Fürst von Waldeck beunruhigte mich noch beim Abschied, denn er sprach von nichts weniger als daß ich bei meiner Rückkehr mich einrichten sollte mit ihm nach Griechenland und Dalmatien zu gehen. Wenn man sich einmal in die Welt macht und sich mit der Welt einläßt, so mag man sich ja hüten daß man nicht entrückt oder wohl gar verrückt wird. $\mathrm{Zu}$ keiner Sylbe weiter bin ich fähig. (IR 278)

Goethe suchte also in Italien das ihm schon Bekannte, ja, man könnte sagen, daß er eigentlich nur sich selber suchte - und fand. Als Ziel der Reise - die somit ganz eindeutig zur Selbstbildungsreise wird - formuliert er explizit: »Ich mache diese wunderbare Reise (...) um mich an den Gegenständen kennen zu lernen.« (IR 49). Die eigene innere Befindlichkeit ist das ausschließlich zu Verwirklichende. Die Italienische Reise wird zum »Prozeß einer gelungenen Selbst-Behauptung « und zum "Modell einer nachhaltigen Selbst-Versicherung ${ }^{29}$, und so heißt es gleich zu Beginn des Zweiten Römischen Aufenthalts:

Laßt mich auch wieder, meine Lieben, ein Wort zu Euch reden. Mir geht es wohl, ich finde mich immer mehr in mich zurück und lerne unterscheiden was mir eigen und was mir fremd ist. Ich bin fleißig und nehme von allen Seiten ein und wachse von innen heraus (IR 425).

Goethe findet in Rom nicht etwa Rom, sondern auch hier immer nur sich selbst: »In Rom hab' ich mich selbst zuerst gefunden, ich bin zuerst übereinstimmend mit mir selbst glücklich und vernünftig geworden (...)«, schreibt er am 14. März 1787 (IR 625). Die Suche nach sich selbst in der Fremde ist allerdings nicht nur Goethe eigen, sondern ist bei den meisten Reisenden, die sich in ein fremdes Land begeben, etwa seit dem 18. Jahrhundert erklärte Absicht der Reise. Zu fragen ist nur, wieso gerade Goethes Selbstfindungsprozeß zum Vorbild für die auf Goethes Spu-

${ }^{27}$ Italo Michele Battafarano, op. cit., 62.

${ }^{28}$ Vgl. hierzu Heinses Brief an Fritz Jacobi vom 15. 9. 1781, in: Wilhelm Heinse, Sämmtliche Werke, hrsg. v. Carl Schüddekopf, Bd. 10: Briefe. Zweiter Band. Von der italiänischen Reise bis zum Tode, Leipzig 1910 (ND München 1977), 138ff. Dieser Eroberungssturm findet laut Dieter Breuer, op. cit., 172 seinen literarischen Niederschlag in dem »nächtlichen römischen Bacchanal Ardinghellos .

${ }^{29}$ Andreas Beyer, op. cit., 665; vgl. hierzu Goethes erstaunte Bemerkung, als er während des Zweiten Römischen Aufenthalts die Arbeit am "Faust « wieder aufnimmt: "Da ich durch die lange Ruhe und Abgeschiedenheit ganz auf das Niveau meiner eignen Existenz zurückgebracht bin; so ist es merkwürdig wie sehr ich mir gleiche und wie wenig mein Innres durch Jahre und Begebenheiten gelitten hat. « (IR 619); vgl. auch IR 625. 
ren reisenden Bildungsbürger werden konnte. Die Erklärung für dieses Phänomen liegt wohl darin, daß Goethes Reiseerfahrungen nur auf den ersten Blick individuell und »ineffabile« erscheinen. Tatsächlich gewinnen sie Musterfunktion für die nachfolgenden Reisegenerationen durch Goethes einmalige Gabe, in der Stilisierung sein subjektives Erleben zum Symbol menschlichen Erlebens überhaupt zu hypostasieren: Der Meister der Selbstvergreisung und der antizipierten Altersweisheit zeigt sich besonders deutlich in den Aschermittwochsbetrachtungen am Ende des römischen Carnevals oder im Räsonnieren über den Fall seiner »schönen Mailänderin«, wobei ihn hier wohl mehr die Zerstörung seines entrückt-verklärenden Bildes von ihr bedrückt als ihr tatsächliches Schicksal. Dieser Habitus wurde allerdings auch durch den Umstand mitbedingt, daß Goethe zum Zeitpunkt der Redaktion der »Italienischen Reise« tatsächlich bereits von seiner Umwelt zum Monument seiner selbst erhoben worden war. Rezeptionsanfällig wurde die »Italienische Reise « dadurch, daß in ihr dem Leser kein selbstkritisches Instrumentarium an die Hand gegeben wird - die Erfahrungen und Identifikationen mit Italien, die eigentlich nur für einen gelten durften, für Goethe selbst nämlich, wurden erst durch ihren Habitus der Allgemeingültigkeit in breiten Schichten adaptierbares Bildungs- und Allgemeingut. Zwei Beispiele sollen im folgenden die Extreme im Spektrum von Goethes Italienerfahrung verdeutlichen: Venedig als Ort der einzigen (und bald überwundenen) Irritation und Sizilien als Schauplatz der stärksten, da künstlerischen und dadurch zugleich authentischsten Annäherung an Italien. ${ }^{30}$

\section{I.2. Goethe in Venedig auf schwankendem Grund}

Venedig nimmt in der »Italienischen Reise « eine Zwischenstellung ein: Einerseits ist das Pathos des Alpenüberstiegs und der gelungenen Flucht aus Karlsbad bereits vergangen, andererseits ist Rom als das ersehnte Ziel der Reise noch nicht erreicht. Der Eintritt in die Lagunenstadt ist zwar großartig, bleibt aber in der Emphase stark hinter dem Romeintritt zurück, der Anlaß zu einer Neudatierung $a b$ urbe intrata gibt und mit einer Wiedergeburt gleichgesetzt wird ${ }^{31}$ Hinzu

\footnotetext{
${ }^{30}$ Vgl. Norbert Miller, Landschaftsmaler, op. cit., 19, der von einem $»$ Dreischritt aus Annăherung (Oberitalien), Erfahrung der Gegenwelt (Rom) und Selbstfindung in der fremden Natur (Sizilien) « spricht, wobei mir der Begriff der "Gegenwelt « für Rom aus obengenannten Gründen problematisch erscheint. Vgl. auch Norbert Miller, Spiegelungen, op. cit., 8: Bis Venedig sei Goethes Italienreise als »bürgerliche Kavaliersreise« angelegt gewesen, mit »angespannter Aufmerksamkeit auf das je Gesehene und Erlebte, auf Kunst und Volksleben, auf den Nutzen von Antike und Renaissance-Kunst für den modernen Künstler (...) «. Nach dem Erlebnis des Übergangs in Venedig wird sie zur reinen Seelenreise.

${ }^{31}$ Jedoch immer noch emphatisch genug: So stand es denn im Buche des Schicksals auf meinem Blatte geschrieben, daß ich 1786 den acht und zwanzigsten September, Abends,
} 
kommt, daß Venedig als die eigentlich italienuntypische, bizarre, fremdartige, »sinnenverwirrende « Stadt Goethe den Rückschlag aus einer Einstimmung erleben läßt, die er meinte, bereits vollzogen zu haben, hatte er doch schon am 22. September aus Vicenza geschrieben: »Ich habe nun erst die zwei italiänischen Städte gesehen und mit wenig Menschen gesprochen, aber ich kenne meine Italiäner schon gut. (IR 67). Venedig wird somit zu einem Ort der Entfremdung, den man »bestehen « muß, um geläutert und gestärkt gegen alle weiteren Anfechtungen weiterreisen zu können. Venedig also in einer eher diffusen Mittel- und Mittlerfunktion welcher Ort wäre wohl angemessener, um eine solche Situation des "schon-nichtmehr, aber auch-noch-nicht « zu verdeutlichen als die Stadt zwischen Land und Meer, auf schwankenden Pfählen erbaut, vom Norden durch die - immer noch sichtbaren - Tiroler Alpen abgeschottet: die "Biberrepublik« (IR 73). Die Venedig-Passage in der »Italienischen Reise « kann als eine der motivisch durchgearbeitetsten des gesamten Textes gelten: Konsequent wird der Aufenthalt als Übergang stilisiert, vor allem das Motiv der selbstgesuchten Isolation und des Incognito wird im Vergleich zum Reisetagebuch deutlich ausgebaut. So wurde die Episode des Zusammentreffens mit den Pilgern auf dem Brenta-Boot in epischer Breite in die Redaktion von 1816/17 eingefügt - man könnte hier auch auf das Motiv des wandernden Harfners verweisen, der wie der Pilger auf der Suche nach einem noch unbekannten höheren Gut durch die Lande zieht und mit dem sich Goethe als italiensuchender Pilger ebenso wie mit den als Landstreicher behandelten »echten" Pilgern identifiziert. Auf eine spätere Parallelstelle sei hier vorerst nur kurz hingewiesen: Goethe stilisiert seine sturmgepeitschte Überfahrt von Neapel nach Sizilien und seine glückliche Ankunft in Palermo als Erlebnisse einer zweiten Odyssee - auch er landet auf der »Insel der seligen Phäaken« (IR 300, 7. 4. 1787). Diese klassischen Phantasien bewegen ihn nicht nur zum Kauf eines Homer, sondern auch zu ersten Ideen für die Bearbeitung des Nausikaa-Stoffes ${ }^{32}$ - doch dazu später mehr.

Eine ganze Kette von Situationen der Mittelstellung, des Übergangs, der Überfahrt, des Halbverstehens reiht Goethe im Venedigteil seines Reiseberichts aneinander: Er sucht seinen Weg - mal mit, mal ohne Plan - durch die »wunderlichsten Irrgänge « (IR 87), er steht in der Kirchentüre zwischen Kapuzinerlitanei und Marktgeschrei (IR 94), er findet sich in einem schwankenden Boot zwischen den singenden Fischern wieder (IR 99). Er erkennt abends in dem Goldoni-Stück, das

nach unserer Uhr um fünfe, Venedig zum erstenmal, aus der Brenta in die Lagune einfahrend, erblicken, und bald darauf diese wunderbare Inselstadt, diese Biberrepublik betreten und besuchen sollte.« (IR 73).

${ }^{32}$ An dieser Stelle wird der hohe Grad der Stilisierung in der Redaktion der »Italienischen Reise « besonders deutlich, tauchte doch im Reisetagebuch bereits in Giredo der Plan für ein Nausikaa-Drama auf: „Sagt ich dir schon daß ich einen Plan zu einem Trauerspiel Ulysses auf Phäa gemacht habe? Ein sonderbarer Gedanke, der vielleicht glücken könnte. « (TB 140, 22. 10. 1786). 
er im Theater sieht, die Szenen wieder, die er tagsüber leibhaftig in den Straßen Venedigs erlebt hat, und seine Bemerkung hierzu könnte metaphorisch für sein langsames Eintauchen ins italienische Volksleben gelesen werden: »(...) so machte es gar große Freude, und ob ich gleich manchen einzelnen Bezug nicht verstand, so konnte ich doch dem Ganzen recht gut folgen.« (IR 109) Um seine anfängliche Unbehaustheit in Venedig zu betonen, beschreibt Goethe mehrfach, wie er sich willentlich im Gewirr der venezianischen Gassen verlor:

Nach Tische eilte ich, mir erst einen Eindruck des Ganzen zu versichern, und warf mich ohne Begleiter, ${ }^{33}$ nur die Himmelsgegenden merkend, ins Labyrinth der Stadt, welche, obgleich durchaus von Kanälen und Kanälchen durchschnitten, durch Brücken und Brückchen wieder zusammenhängt. (IR 79)

Gegen Abend verlief ich mich wieder, ohne Führer, in die entferntesten Quartiere der Stadt. (...) Ich suchte mich in und aus diesem Labyrinth zu finden, ohne irgend jemand zu fragen, mich abermals nur nach der Himmelsgegend richtend. Man entwirrt sich wohl endlich, aber es ist ein unglaubliches Gehecke in einander (...). (IR 80/81)

Der Versuch, sich einen »Eindruck des Ganzen zu versichern« und sich aus dem kleinteiligen Gassengewirr zu befreien, erfolgt hier wie schon vorher in Verona (IR 47) und Padua (IR 68) durch den Blick über die Stadt von einem Turm aus in Venedig vom Campanile auf dem Markusplatz. Erst nach dem venezianischen Aufenthalt läßt dieses Orientierungsbedürfnis von erhobenem und enthobenem Standpunkt aus langsam zugunsten eines Eintauchens in und »Erlaufens « der besichtigten Städte nach. Auch die Kette der nördlichen Berge, in deren Bannkreis sich Goethe bis dahin bei seinen Rundblicken immer noch befand, werden dann dem Blick entzogen. Ebenfalls seltener werden die Jugenderinnerungen z.B. an das venezianische Gondelmodell im Elternhaus - und der geistige Austausch mit dem Vater (IR 80).

Goethe ist in Venedig nicht nur einsam, sondern auch stumm - er vermeidet bewußt jede Kommunikation, wobei diese Stummheit wohl zum Teil auch auf seine mangelnden sprachlichen Fähigkeiten (vor allem im venezianischen Dialekt) zurückzuführen ist. Als Gegenbild zu seiner eigenen Sprachlosigkeit und seiner unsicheren und unentschiedenen Position wird das ständig redende und wild gestikulierende venezianische Volk gezeichnet. Für den Venezianer ist seine Stadt kein Territorium zwischen den Welten, sondern der ihm eigene Lebensbereich, und er bewegt sich sicher diesseits und jenseits des Canal grande:

Die beiden Hauptteile von Venedig, welche der große Kanal trennt, werden durch die ein-

${ }^{33}$ „Ohne Begleiter« ist Goethe allerdings erst nach seinem redaktionellen Eingriff in den Text, denn im Tagebuch finden sich mehrere Erwähnungen eines Lohnbediensteten, der dem Reisenden gute Dienste leistete, dessen jovialer Umgang jedoch nicht so recht zum »nordischen Flüchtling « passen wollte. Daher wird er nicht in die »Reise «übernommen an zwei Stellen vergaß der Redaktor allerdings, die Spuren seines Dieners zu tilgen, so da $\mathrm{B}$ in der Episode des Schiffergesangs recht unmotiviert ein dem Leser unbekannter "Alter « zu sprechen beginnt (IR 100); auch wird nicht klar, wer mit dem $»$ Schutzgeist $\alpha$ gemeint ist, der Goethe auf den Lido begleitet (IR 104). 
zige Brücke Rialto miteinander verbunden, doch ist auch für mehrere Kommunikation gesorgt, welche in offenen Barken an bestimmten Überfahrtspunkten geschieht. (IR 80$)^{34}$

Doch dieses »natürliche « Sich-Bewegen in der Lagunenstadt - »natürlich « ist ein ständig wiederkehrendes Schlüsselwort zur Bezeichnung des Volkes - ist nur einem Ureinwohner möglich, einem Seßhaften, nicht jedoch dem fremden Durchreisenden. Diesem präsentiert sich die Stadt zwar auch als Organismus, jedoch eben als ein abgeschlossener, ihm in seiner Fremdheit gegenübergestellter:

Nun [nach der Flucht auf die Inseln] drängten sich die Wohnungen enger und enger, Sand und Sumpf wurden durch Felsen ersetzt, die Häuser suchten die Luft wie Bäume die geschlossen stehen, sie mußten an Höhe zu gewinnen suchen, was ihnen an Breite abging. Auf jede Spanne des Bodens geizig, und gleich anfangs in enge Räume gedrängt, ließen sie zu Gassen nicht mehr Breite, als nötig war eine Hausreihe von der gegenüberstehenden zu trennen, und dem Bürger notdürftige Durchgänge zu erhalten. Übrigens war ihnen das Wasser statt Straße, Platz und Spaziergang. Der Venetianer mußte eine neue Art von Geschöpf werden, wie man denn auch Venedig nur mit sich selbst vergleichen kann. (IR 78/79)

Doch trotz aller Unbehaustheit und Fremdheit wäre Goethe nicht Goethe, wenn es ihm nicht gelänge, diesen irritierenden Zustand recht bald in einen beruhigten zu überführen. Ganz allein muß er diese Aufgabe allerdings nicht bewältigen, denn er hat sich noch vom Festland einen Führer mit nach Venedig gebracht, der ihm in der Stadt wertvolle Dienste leistet und ihn letztendlich auch aus dem Labyrinth der sinnenverwirrenden Stadt hinausgeleitet: Ich spreche von Palladio, der nach Goethes eigenen Aussagen ihm den Weg zur Antike »und zu aller Kunst und Leben« (IR 103) - und damit nach Rom - geöffnet hat. Und so zieht es Goethe am Ende seines Venedigaufenthalts unaufhaltsam auf das »feste Land « (IR 114), der schwankende Grund wird nach der vollzogenen Initiation gegen die terra ferma eingetauscht. Goethe betrachtet den Übergang am 12 . Oktober 1786 als vollzogen, die Entfremdung ist überwunden, und er schreibt resümierend:

Ich bin nur kurze Zeit in Venedig, und habe mir die hiesige Existenz genugsam zugeeignet, und weiß, daß ich, wenn auch einen unvollständigen, doch einen ganz klaren und wahren Begriff wegnehme. (IR 113/114)

Während des Venedigaufenthalts deutet sich jedoch noch ein weiterer, möglicher Zugang zu Italien an, der bereits im Giardino botanico in Padua formuliert worden war (IR 69) und der seinen emphatischen Ausdruck in Goethes oft zitiertem Ausruf angesichts der »Wirtschaft der Seeschnecken, Patellen und Taschenkrebse « findet: "Was ist doch ein Lebendiges für ein köstliches, herrliches Ding! Wie abgemessen zu seinem Zustande, wie wahr, wie seiend!« (IR 108). Die Natur wird somit zum Leitmotiv der Weiterreise, kulminierend in Goethes Sizilienerlebnis.

${ }^{34} \mathrm{Zu}$ diesem »kommunikativen « Aspekt vgl. auch IR 106, wo von den »KommunikationsKanälen« zwischen Lagune und offenem Meer die Rede ist. 


\section{I.3. Goethe auf »überklassischem Boden«}

In dem Schlüsselbrief, den Goethe am 17. Mai 1787 aus Neapel, unmittelbar nach seiner Rückkehr aus Sizilien, an Herder schreibt, evoziert er in charakteristischer Engführung die drei großen Themen, die seinen Großgriechenlandaufenthalt zu der alles entscheidenden Etappe seiner Italienreise werden ließen, zum »Wunder seiner sizilianischen Metamorphose ${ }^{35}{ }^{35}$ Es sind dies die griechische Kunst, speziell die Tempel von Paestum, weiterhin das »Geheimnis der Pflanzenerzeugung und Organisation « (IR 393), die berühmte Urpflanze also, und schließlich - als Bindeglied zwischen Kunst- und Naturerlebnis - die Dichtung Homers. Die Bedeutung des Sizilienerlebnisses für Goethe liegt darin, daß sich ihm während seines Aufenthaltes auf dem »überklassischen Boden« (IR 369) diese drei Hauptpräokkupationen zu einem Ganzen zusammenschließen: Sizilien wird zum Erlebnis der Identität von Kunst und Natur, der ganzheitlichen Geschlossenheit, ein alle Sinne ansprechendes, quasimythisches Naturerlebnis, das zugleich den Schlüssel für eine Kunsterkenntnis bietet, die ihr Ideal im griechischen Kosmosverständnis hat. Das Ideal einer organischen Kunst, in der jedes Einzelteil, jede Schmuckform in notwendigem Zusammenhang mit dem Ganzen und seiner Funktion steht, ${ }^{36}$ hatte Goethe schon in anschaulichster Weise anhand seiner Beschreibung des Amphitheaters in Verona evoziert, die seine Vorstellung von dem Prozeß der Kunstgenese exemplarisch wiederspiegelt:

Wenn irgend etwas Schauwürdiges auf flacher Erde vorgeht und alles zuläuft, suchen die Hintersten auf alle mögliche Weise sich über die Vordersten zu erheben: man tritt auf Bänke, rollt Fässer herbei, fährt mit Wagen heran, legt Bretter hinüber und herüber, besetzt einen benachbarten Hügel und es bildet sich in der Geschwindigkeit ein Krater. Kommt das Schauspiel öfterer auf derselben Stelle vor, so baut man leichte Gerüste, für die so bezahlen können, und die übrige Masse behilft sich wie sie mag. Dieses allgemeine Bedürfnis zu befriedigen ist hier die Aufgabe des Architekten. Er bereitet einen solchen Krater durch Kunst, so einfach als nur möglich, damit dessen Zierat das Volk selbst werde. Wenn es sich so beisammen sah, mußte es über sich selbst erstaunen, denn da es sonst nur gewohnt, sich durch einander laufen zu sehen, sich in einem Gewühle ohne Ordnung und sonderliche Zucht zu finden, so sieht das vielköpfige, vielsinnige, schwankende hin und her irrende Tier, sich zu einem edlen Körper vereinigt, zu einer Einheit bestimmt, in eine Masse verbunden und befestigt, als Eine Gestalt, von Einem Geiste belebt. Die Simplizität des Oval ist jedem Auge auf die angenehmste Weise fühlbar und jeder Kopf dient zum Maße, wie ungeheuer das Ganze sei. Jetzt wenn man es leer sieht, hat man keinen Maßstab, man weiß nicht ob es groß oder klein ist. (IR 42f.)

Doch erst auf Sizilien wird die völlige Identifikation mit einem Italienbild möglich, das der klassische Reisende Goethe schon in den Antiken Oberitaliens gesucht hatte, denn nur in Großgriechenland weht noch der ersehnte Wind über

\footnotetext{
${ }^{35}$ Norbert Miller, Landschaftsmaler, op. cit., 17.

${ }^{36} \mathrm{Vgl}$. hierzu Goethes Ausführungen in der Baukunst $«$ von 1795, in: Münchner Ausgabe, Bd. 4.2, hrsg. v. Klaus H. Kiefer u.a., München 1986, 53-60; vgl. Goethes Zeichnungen ibid., die die Entstehung der griechischen Schmuckformen verdeutlichen sollen.
} 
den Rosenhügel ${ }^{37}$, und es kann dem Reisenden offenbarungsgleich die Erkenntnis über das Wesen antiker Kunst »wie eine Decke von den Augen« fallen (IR 393). Goethe verwandelt sich in der klassischen Umgebung selbst in einen Odysseus, der nach langer, sturmgepeitschter Fahrt ins glückselige Land der Phäaken gelangt. $^{38}$ Im Garten von Palermo schreibt er am 7. April 1787:

Welche wundersame Ansicht ein solcher Duft entfernterern Gegenständen, Schiffen, Vorgebirgen erteilt, ist für ein malerisches Auge merkwürdig genug, indem die Distanzen genau zu unterscheiden, ja zu messen sind; deswegen auch ein Spaziergang auf die Höhe höchst reizend ward. Man sah keine Natur mehr, sondern nur Bilder, wie sie der künstlichste Maler durch Lasieren auseinander gestuft hätte. Aber der Eindruck jenes Wundergartens war mir zu tief geblieben; die schwärzlichen Wellen am nördlichen Horizonte, ihr Anstreben an die Buchtkrümmungen, selbst der eigene Geruch des dünstenden Meeres, das alles rief mir die Insel der seligen Phäaken in die Sinne so wie ins Gedächtnis. Ich eilte sogleich einen Homer zu kaufen (...). (IR 299f.)

Das einmalige Naturerlebnis wird sogleich mit Gestalten aus der Antike belebt, die sich Goethe aus der Betrachtung antiker Vasen und Sarkophage buchstäblich zusammensucht. ${ }^{39}$ Italien wird ihm zum Land der realisierten »ersten [i.e. höchsten] poetischen Ideen«, wie er schon anhand der »homerischen Haushaltung « in Foligno bemerkt hatte (IR 139). Und so verwundert es nicht, daß diese Umgebung, in der sich Natur und Kunst sichtbar gegenseitig durchdringen, Goethe zur einzigen neuen poetischen Produktion in Italien inspiriert und ihn in eine "poetische Stimmung (IR 369) versetzt: Angeregt durch die Besichtigung das Theaters von Taormina, dieses »ungeheuerste(n) Natur- und Kunstwerk(s)« (IR 363) gibt Goethe "einem nach und nach auflebenden Drange nach: die gegenwärtige herrliche Umgebung, das Meer, die Inseln, die Häfen, durch poetische würdige Gestalten zu beleben und mir auf und aus diesem Local eine Komposition zu bilden, in einem Sinne und in einem Ton, wie ich sie noch nicht hervorgebracht.« (IR 367)

${ }^{37}$ Vgl. IR 44, Verona, am 16. September 1786.

${ }^{38}$ »Es war in dieser Komposition nichts was ich nicht aus eignen Erfahrungen nach der Natur hätte ausmalen können. Selbst auf der Reise, selbst in Gefahr Neigungen zu erregen, die, wenn sie auch kein tragisches Ende nehmen, doch schmerzlich genug, gefährlich und schädlich werden können; selbst in dem Falle in einer so großen Entfernung von der Heimat abgelegne Gegenstände, Reiseabenteuer, Lebensvorfälle zu Unterhaltung der Gesellschaft mit lebhaften Farben auszumalen, von der Jugend für einen Halbgott, von gesetztern Personen für einen Aufschneider gehalten zu werden, manche unverdiente Gunst, manches unerwartete Hindernis zu erfahren (...).« (IR 369)

${ }^{39}$ Unschwer läßt sich in der Beschreibung der Vase im Dom von Agrigent die Ankunftsszene des Odysseus bei den Phäaken erkennen: „Von der Vase des Doms noch ein Wort. Auf derselben steht ein Held in völliger Rüstung, gleichsam ein Ankömmling, vor einem sitzenden Alten der durch Kranz und Szepter als König bezeichnet ist. Hinter diesem steht ein Weib, das Haupt gesenkt, die linke Hand unter dem Kinn; aufmerksam-nachdenkende Stellung. Gegenüber hinter dem Helden ein Alter, gleichfalls bekränzt, er spricht mit einem spießtragenden Manne, der von der Leibwache sein mag. Der Alte scheint den Helden eingeführt zu haben und zu der Wache zu sagen: laßt ihn nur mit dem König reden, es ist ein braver Mann.« (IR 347); vgl. auch IR 336. 
»Aus der Erinnerung « ist der Abschnitt überschrieben, in dem er seine wunderbare Vision einer mit antiken Gestalten belebten ursprünglichen Natur im Garten unterhalb von Taormina entwirft. Die utopische Hoffnung, die dann auch charakteristischerweise nicht in die Realität umzusetzen ist, ${ }^{40}$ besteht darin, zu einem zweiten Homer zu werden und wie dieser den Übergang von Natur in Kunst flieBend zu machen, selbst demiurgisch einen Mythos zu schaffen, der menschliches Schicksal in erkennbare und erlebbare natürliche Gegebenheiten einbindet und in dem die Statue nicht mehr von der lebendigen Gestalt zu unterscheiden ist, in dem der Felsblock im Meer tatsächlich das versteinerte Schiff der Phäaken ist. ${ }^{41}$ Doch »Nausikaa« bleibt ein Fragment - wie übrigens auch die 1799 begonnene "Achilleis«. An Spekulationen und Erklärungsversuchen für das Scheitern des poetischen Entwurfs mangelt es in der Literatur nicht: Sei es die »Einsicht von der uneinholbaren Ferne des Mythos, von seiner Nicht-mehr-Verfügbarkeit «, vermittelt durch die "Anwesenheit am Ort des Mythos «, ${ }^{42}$ sei es die "unmittelbare, unvermittelte und somit unvermittelbare Gegenwart der »sizilianischen Epipha-

${ }^{40}$ Utopisch ist diese Hoffnung, weil sie dem Versuch gleichkäme, ein mythisches (somit unhistorisches) Erlebnis im nachhinein poetisch-diskursiv fassen zu wollen. Norbert Miller, Spiegelungen, op. cit., verweist darauf, daß die Identität Natur-Kunst für Goethe nur am »zeitenthobenen Ort« (31) auf Sizilien in der »Versinnlichung « (36) erlebbar gewesen sei. Dieses Erlebnis einer vorhistorisch-archaischen Welt schließe jedoch die ästhetischhistorische Annäherung daran aus. Eben darum habe "Goethe, seit er auf Sizilien weilt, alle Geschichtlichkeit aus seinem Denken verbannt.« (28).

${ }^{41} \mathrm{Vgl}$. hierzu die Interpretation Burckhardts in seinem Vortrag »Das Phäakenland Homers « vom 14. November 1876, in: Jacob Burckhardt Gesamtausgabe, Bd. XIV, hrsg. v. Emil Dürr, Berlin/Leipzig 1933, 164-177; dort v.a. 164, 170, 175; vgl. auch seine Beschreibung von Rubens' Landschaft »Nausikaa « im »Cicerone «, wo es heißt, die Nausikaa erhebe uns »mit ihrer reichen Fels- und Seelandschaft und ihrer phantastischen Beleuchtung (...) in den Mitgenuß eines fabelhaften Daseins «, in: id., Der Cicerone, Stuttgart 1986, 996. Die Gleichsetzung von Rubens' schöpferischer Kraft mit der Homers findet sich auch in dem emphatischen Schluß der »Erinnerungen aus Rubens « (Gesamtausgabe, Bd. XIII, hrsg. v. Felix Stähelin u. Heinrich Wölfflin, Berlin/Leipzig 1934, 517), wo dieselbe Landschaft evoziert wird: „Endlich aber, in einem der herrlichsten Bilder des ganzen Palazzo Pitti, nehmen die Sturmwolken über dem Meere ihren Abschied, und in der Höhe, als ferne ätherische Erscheinung, sieht man Pallas bittend vor Jupiter; weiche warme Morgenlüfte nehmen den übrigen Horizont ein, und im schönsten Fabellicht ragt ein Gebirge steil empor, mit Wasserfällen, Burgen und einer Gartenanlage von Terrassen und Prachtbauten. Es sind die Gärten des Alkinoos, Königs der Phäaken, deren Hafenstadt in der Ferne sichtbar wird. Im Vordergrunde erscheint, bittend und nackt, der schiffbrüchige Odysseus, für welchen sich Pallas bei Jupiter verwendet hat, und die Königstochter, deren Dienerinnen hatten vor ihm flüchten wollen, verfügt mit ruhigem Gebot, wie ihm mit Kleidung zu helfen sei; es ist Nausikaa. So treffen sie denn zusammen, Der aus Jonien und Der aus Brabant, die beiden größten Erzähler, welche unser alter Erdball bis heute getragen hat, Homer und Rubens."

${ }^{42}$ Jörg-Ulrich Fechner, nzugleich völlig wahrhaft und ein anmuthiges Märchen«: Goethes Italienische Reise - keine Reisebeschreibung!, in: Italienische Reise, Reisen nach Italien, op. cit., 231-255, hier 252; vgl. auch Norbert Miller, Spiegelungen, op. cit. 
nie Homers « und des Altertums, ${ }^{43}$ die zu große Einstimmung, die Abwesenheit der für jede künstlerische Produktion notwendigen Differenz von Natur und Kunst, oder sei es gar, wie Osterkamp meint, ${ }^{44}$ Goethes mangelndes Verhältnis zur tragisch-heroischen Zerstörung, die nicht mit seinem Bild von der formbildenden, lebendigen, gesunden Antike, der »reinen hochkräftigen Natur «, zu vermitteln war, ${ }^{45}$ feststeht, daß der bleibende Gewinn von Goethes Sizilienaufenthalt kein poetisches Kunstwerk ist. Dennoch wird ein »Schlüssel«, ein »Modell«, ein "Gesetz « (IR 313, 394) hinüber aufs italienische Festland, ja bis in den heimischen Norden, gerettet, ein Schlüssel, dem Goethe schon in Padua begegnet war, der aber erst im südlichen Landschaftserlebnis ganz faßbar wird: die Urpflanze. ${ }^{46}$

Es erstaunt nicht, daß Goethe sich nach Sizilien, nach seiner bahnbrechenden Findung also, von allem Neuen abkehrt und sich zunehmend auf sich selbst zurückbindet - der Zweite Römische Aufenthalt ist eine »Revision« und Vertiefung des schon Bekannten. Es erstaunt auch nicht, daß er den Gedanken an eine authentische poetische Produktion zugunsten der Überarbeitung schon bestehender Werke für die geplante Gesamtausgabe aufgibt. Nicht von ungefähr befällt ihn am 17. Mai 1787 in Neapel erstmals das Gefühl von Heimweh - "mit Sizilien und Neapel endete für Goethe auch in der Erinnerung der Bildungsweg seiner Italienreise. ${ }^{47}$ Doch der einmal gefundene Generalschlüssel, der gleichermaßen Natur und Kunst aufschließt, wird wie ein Geheimnis gehütet und soll fortan universell zur Anwendung gebracht werden: Die »Metamorphose der Pflanzen « erscheint 1790, Caroline Herder berichtet ihrem Gatten von Goethes Plan, nach der Italienreise alle gesetzmäßigen Abwandlungen des Typus' Mensch in einem Werk über menschliche Charaktere darzustellen ${ }^{48}$ und 1795 sollte in Zusammenarbeit mit Heinrich Meyer das große kultur- und kunstmorphologische Italienwerk entstehen. Nicht nur die Natur wird von Goethe nach seinem sizilianischen Damaskus als sich ständig metamorphotisch verändernder Organismus betrachtet, sondern auch die Stilgenese in der Kunst ist durch den Prozess einer stetigen Formgenese durch Anreicherung und Wachstum zu erklären. ${ }^{49}$ Man könnte sagen: Erst durch

\footnotetext{
${ }^{43}$ Wilfried Barner, op. cit., 83.

${ }^{44}$ Ernst Osterkamp, op. cit., 170.

${ }^{45}$ Meint dies Burckhardt, wenn er in seinem Phäaken-Vortrag (op. cit., 176) schreibt: „Vielleicht aber fand Goethe in seinem Entwurf einen tiefern, das Leben der Tragödie in Frage stellenden Mangel und ließ sie deshalb liegen.«?

${ }^{46} \mathrm{Vgl}$. Goethes Brief an Knebel vom 18. 8. 1787, Goethes Briefe, op. cit., Nr. 450, 64: »Ich hoffe du wirst auch dereinst an meiner Harmonia Plantarum, wodurch das Linnéische System aufs schönste erleuchtet wird, alle Streitigkeiten über die Form der Pflanzen aufgelöst, ja sogar alle Monstra erklärt werden Freude haben.«

${ }^{47}$ Norbert Miller, Landschaftsmaler, op. cit., 18.

${ }^{48} \mathrm{Vgl}$. Wanda Kampmann, op. cit., 459.

${ }^{49}$ Hans Pyritz, Goethe-Studien, hrsg. v. Ilse Pyritz, Köln/Graz 1961, 28 spricht von Goethes italienischer "Natur- und Kunstmorphologie «; diese Methode einer morphologischen Betrachtung der Kunstentwicklung wird in der Folge dann bei Jacob Burckhardt und Heinrich Wölfflin zentral. Zurückzuführen ist sie nicht allein auf Goethe, sondern auch in
} 
seine Einblicke in die Funktionsprinzipien der Natur fühlt Goethe sich imstande, selbstschöpferisch eben diese Prinzipien auf eine mythische Poesie anzuwenden, und diesen Akt könnte man als »überklassisch «, da nur durch den Einblick in die klassische Vorstellung von Natur und Kunst erreichbar, bezeichnen.

Auf die Frage, ob die Begegnung mit den antiken Tempeln in Agrigent auch den Wandel von Goethes Paestum-Beurteilung erklären kann, möchte ich an dieser Stelle kurz eingehen. Goethe, dessen Anschauung von griechischen Tempeln durch den korinthisch-verspielt-leichten Minerva-Tempel in Assisi vorgeprägt war, ${ }^{50}$ zeigte sich bei seinem ersten Besuch in Paestum von »diesen stumpfen, kegelförmigen, enggedrängten Säulenmassen« eher befremdet, ja, sie erschienen ihm »fremd« und »furchtbar « (IR 274f.). Man fühlt sich an die bedeutungsschweren Anfangssätze aus Burckhardts »Cicerone« erinnert:

Von den drei erhaltenen Tempeln der alten Poseidonia sucht das Auge sehnsüchtig den größten, mittlern. Es ist Poseidons Heiligtum; durch die offenen Trümmerhallen schimmert von fern das blaue Meer. Ein Unterbau von drei Stufen hebt das Haus des Gottes über die Fläche empor. Es sind Stufen für mehr als menschliche Schritte. ${ }^{51}$

Doch schon bald wird die durch das Archaische hervorgerufene Beunruhigung überwunden, »in weniger als einer Stunde « fühlt Goethe sich »befreundet « (IR 275). Er wagt die mehr als menschlichen Schritte und versucht, sich das eigentliche Leben dieser »länglich-viereckigen Massen« steigend, laufend, durchdringend anzueignen, sich mit ihm gewissermaßen physisch anzufreunden und so einen Maßstab für das Fremd-Numinose zu gewinnen: In Agrigent verfährt Goethe ebenso, indem er sich in die immens erscheinenden Kanneluren hineinstellt, ${ }^{52}$ sie in Relation zu seinen eigenen menschlichen Maßen bringt und sich dadurch einen »Begriff « von ihnen vermittelt (IR 340). ${ }^{53}$

Erst nach dem Erlebnis der sizilianischen Tempel, die in ihrer Schlankheit

hohem Maße auf die grundlegenden Untersuchungen von Alexander von Humboldt in den Tableaux de la Nature « und im »Kosmos «.

${ }^{50}$ Hier wurde Goethe, wie Andreas Beyer gezeigt hat, an seinem »Führer Palladio irre; vgl. id., Kunstfahrt und Kunstgebilde, in: Goethe und die Kunst. Ausstellungskat., hrsg. v. Sabine Schulz, Frankfurt a. M. 1994, 447-454. Doch bedurfte Goethe auch in der Folge einer Führung, die er in der Kunstgeschichte als einer Geschichte der metamorphotischen Formgenese zu finden hoffte.

${ }_{52}^{51}$ Jacob Burckhardt, Der Cicerone, op. cit., 3.

${ }^{52}$ Als Nothelfer in dieser Situation zeitweiliger Beunruhigung wird Riedesel angerufen, der alle Tugenden des Unerschütterlichen besitzt: „Aus frommer Scheu habe ich bisher den Namen nicht genannt des Mentors, auf den ich von Zeit zu Zeit hinblicke und hinhorche; es ist der treffliche von Riedesel, dessen Büchlein ich wie ein Brevier oder Talisman am Busen trage. Sehr gern habe ich mich immer in solchen Wesen bespiegelt, die das besitzen, was mir abgeht und so ist es grade hier: ruhiger Vorsatz, Sicherheit des Zwecks, reinliche, schickliche Mittel, Vorbereitung und Kenntnis, inniges Verhältnis zu einem meisterhaft Belehrenden, zu Winckelmann; dies alles geht mir ab und alles übrige was daraus entspringt.« (IR 343f.); vgl. hierzu Norbert Miller, Spiegelungen, op. cit., $25 \mathrm{f}$.

${ }^{53} \mathrm{Vgl}$. hierzu die schon zitierte Parallelstelle bei der Beschreibung des Amphitheaters in Verona: »(...) jeder Kopf dient zum Maße, wie ungeheuer das Ganze sei. Jetzt wenn man 
schon eher »unserem Maßstabe des Schönen und Gefälligen« entsprächen und sich zu Paestum verhielten »wie Göttergestalt zum Riesenbilde« (IR 340), revidiert er in dem schon erwähnten Brief an Herder sein Urteil über Paestum und kommt zu der überraschenden und interpretationsbedürftigen Aussage:

In einem beiliegenden Blatte sag' ich etwas über den Weg nach Salern und über Pestum selbst; es ist die letzte und fast möcht' ich sagen herrlichste Idee, die ich nun nordwärts vollständig mitnehme. Auch ist der mittlere Tempel, nach meiner Meinung, allem vorzuziehen, was man noch in Sizilien sieht. (IR 393)

Hier scheinen sich zwei Motivationen für die Aufwertung Paestums zu verbinden, ${ }^{54}$ wobei die Betonung in dem zitierten Textabschnitt wohl auf die »Idee « und auf »vollständig« zu legen ist. Einerseits unterstreicht Goethe mehrfach, daß sich die Tempel in Paestum durch ihren guten Erhaltungsgrad auszeichnen - er spricht explizit von den »so wohl erhaltenen Resten« (IR 275) -, während er in Agrigent auf die natürliche und durch menschliche Restaurationsversuche hervorgerufene Zerstörung der antiken Bauwerke hinweist (IR 340f.). Selinunt »liegt methodisch umgeworfen« (IR 385), ein Umstand, der Goethe von der Besichtigung abhält. Fern aller Ruinenromantik, ist ihm der Anblick der Zerstörung unerträglich, widerspricht er doch seiner Auffassung von der bildenden Natur und dem Höhepunkt der Natur nachbildenden Kunst im unversehrten Kunstkörper der Antike. ${ }^{55}$ Andererseits werden die Tempel von Paestum, integriert in einen morphologisch verstandenen Stilablauf und kunsthistorisch-distanzierend der direkt erschüttern-

es leer sieht, hat man keinen Maßstab, man weiß nicht ob es groß oder klein ist.« (IR 42f.).

${ }^{54}$ Die in der Literatur vertretenen Thesen zu diesem Urteilswandel sind zahlreich: Ermöglichte das Wiedersehen Paestums den Vergleich mit Agrigent und die Würdigung, die Einordnung und »Rückführung auf die Urformen klassischer Architektur « (Jörn Göres, ")Wie wahr! Wie seiend! Reflexionen zu Goethes Italien-Reisen«, in: GJb 105 (1988), 11-26, hier 19)? Bedeutete die Rückbesinnung auf die Kunstgeschichte (vgl. IR 275: "Doch nahm ich mich bald zusammen, erinnerte mich der Kunstgeschichte, gedachte der Zeit deren Geist solche Bauart gemäß fand, vergegenwärtigte mir den strengen Styl der Plastik und in weniger als einer Stunde fühlte ich mich befreundet, ja ich pries den Genius daß er mich diese so wohl erhaltenen Reste mit Augen sehen ließ, da sich von ihnen durch Abbildung kein Begriff geben läßt.«) zugleich die notwendige historische Distanzierung und somit Verständnis für das vorher Unbegreifliche (Ferdinand van Ingen, op. cit., 188)? Oder vollzog Goethe »an sich selbst die Entwicklung der Bauart, die sErziehung des Säulengeschlechts^ durch die Jahrhunderte « und bildete sich so aus der Natur zur Kunst (Marianello Marianelli, op. cit., 127)? Ich versuche im folgenden eine weitere Interpretation der Stelle.

${ }^{55} \mathrm{Vgl}$. Wanda Kampmann, op. cit., 406: »Denn das ist immer zu unterscheiden: wenn Goethe die Kunstformen bei der Betrachtung so behandelt wi e Gebilde der Natur, wie Pflanzen und Steine, so sieht er sie doch nicht a Is Natur, nicht in einer alles verbindenden und alle Grenzen verwischenden Einheit des Gefühls. Deshalb ist ihm der Zerfall der von Menschenhand gebildeten Formen und die Rückkehr in die formlose Natur ein peinlicher und unerträglicher Anblick, ein Bild der Zerstörung und Zersetzung, nicht der erhabenen Trauer über die Vergänglichkeit aller menschlichen Werke.«; vgl. auch die Entgegensetzung "gebildete Massen« (IR 201) und »überreiche Trümmer« (IR 195). 
den Anschauung entzogen, zu einem Teil des Metamorphoseprozesses, dessen Prinzip Goethe erst auf Sizilien in seiner ganzen Tragweite erkannt hatte. Der »an Paestum gewonnene entwickelte Gedanke« wäre somit der Metamorphosegedanke aller Formen - der natürlichen wie auch der künstlerischen. So wird über diesen Metamorphosegedanken letztendlich doch eine Vermittlung des vermeintlich Inkommensurablen möglich: Durch ihn wird das Archaisch-Mythische mit dem zeitgenössischen "Maßstab des Schönen und Gefälligen « verbindbar. Als »Idee « können die bei erster Betrachtung als archaisch-bedrohlich empfundenen Gesteinsmassen in den Ablauf der Kunstgeschichte eingebunden und dadurch »ruhiggestellt« werden - eben dies spräche jedoch für die heute in der Forschung vertretene Annahme, daß Goethe kein zweites Mal nach Paestum reiste, ${ }^{56}$ sondern nur seine durch die sizilianische Erfahrung modifizierte Erinnerung retrospektiv in die neugewonnene sizilianische Kulturmorphologie eingliederte.

Die Urpflanze - mag sie nun Idee oder Realität sein - wird nach dem Sizilienaufenthalt zum universellen erkenntnisleitenden Prinzip Goethes, zur »Kombination der Kunst mit meiner Vorstellungs-Art der Natur $«{ }^{57}$ Der poetisch belebte Wundergarten des Alkinous verwandelt sich in einen $»$ Weltgarten ${ }^{58}$, der die Funktionsprinzipien alles Lebendigen erschließt; die poetische Idee und die potentiell überschießende Einbildungskraft, die »malerischen(n) und dichterische(n) Schatten und Scheine« (IR 394) werden der sicheren Erkenntnis einer »innerliche(n) Wahrheit und Notwendigkeit« und der beruhigenden Erklärung geopfert. $^{59}$ Dennoch:

Mit Goethe ist nicht zu rechten. Schmerzlich wäre es, denken zu müssen, daß botanische Präokkupationen wegen der Urpflanze auf Kosten der Tragödie jene weihevollste und vielleicht entscheidende Stunde im Garten von Palermo (17. April 1787) möchten vorweggenommen haben; denn die botanische Wissenschaft würde auch ohne Goethe, so wie zum Beispiel die Wasserbaukunst und Mechanik auch ohne Lionardo da Vinci, auf alle

${ }^{56}$ Vgl. den Kommentar zur IR, 1065; vgl. Norbert Miller, Spiegelungen, op. cit., 38.

${ }^{57}$ Vgl. Brief an Knebel vom 3. 10. 1787, in: Goethes Briefe, op. cit., Bd. II, Nr. 452, 66: "Kaum war die erste Begierde des Anschauens gesättigt, kaum hatte sich mein Geist aus der Kleinheit der Vorstellungsart die uns Ultramontanen mehr oder weniger anklebt, erhoben; so sah ich mich schnell nach den besten und sichersten Wegen um. Ich fand sie leicht und gehe nun Schritt vor Schritt darauf hin, langsam aber sicher, als wenn es mein Metier werden sollte und so, daß ich einen festen Grund habe, auf dem ich, selbst in der Entfernung von diesen Gegenden, zwar langsam, doch gewiß fortbauen kann. Glücklicherweise hab ich auch eine Kombination der Kunst mit meiner Vorstellungs-Art der Natur gefunden und so werden mir beide doppelt lieb.«

${ }^{58} \mathrm{Vgl}$. IR, 17. April 1787, 327: „Gestört war mein guter poetischer Vorsatz, der Garten des Alcinous war verschwunden, ein Weltgarten hatte sich aufgetan.«

${ }^{59} \mathrm{Vgl}$. Wilhelm Emil Mühlmann, "Goethe, Sizilien und wir «, in: Germanisch-Romanische Monatsschrift NF 26 (1976), 440-451, hier 446: »Es ist und bleibt ein Jammer, daß Goethe den Plan der Nausikaa nicht ausgeführt hat, da ihm die Präokkupation durch die Idee der ,Urpflanze ‘ dazwischenkam. Denn dieser Plan wäre die vollendete Anverwandlung des homerischen Traums geworden, ein wahrhafter Beitrag zur Weltliteratur, mehr als die blasse Iphigenie, weil in der Landschaft des Südens erlebt (...).« 
ihre wirklichen Wahrheiten und Entdeckungen geraten sein, während die großen Schöpfungen der Poesie und Kunst nur an ganz bestimmte große Meister gebunden sind und ungeboren bleiben, wenn diese ihre Kräfte anderweitig verwenden. Vielleicht aber fand Goethe in seinem Entwurf [der Nausikaa] einen tiefern, das Leben der Tragödie in Frage stellenden Mangel und ließ sie deshalb liegen. Und doch wäre in jener Zeit seiner hohen, geläuterten Kraft auch bei einer nicht tadelfreien Anlage immer noch ein herrliches Werk entstanden, und in den hingeworfenen Fragmenten aus den Reden und dem Dialog der Tragödie finden sich einzelne Zeilen, die zum wunderbarsten und lieblichsten gehören, was Goethe gesagt hat. Vollends der südliche Ton und Klang, welcher das Ganze würde durchdrungen haben, ist durch keine andere Dichtung Goethes zu ersetzen: »Ein weißer Glanz ruht über Land und Meer/Und duftend schwebt der Äther ohne Wolken.. ${ }^{60}$

Derjenige, der hier mit Goethes Worten Claud'sche Nachmittagsdüfte »auf ferne Meere breitet ${ }^{61}$ und somit die natürliche zur klassischen Landschaft hypostasiert, ist niemand anders als der vielleicht einzige tatsächliche Nachfolger Goethes unter den Italienliebhabern und -beschreibern im 19. Jahrhundert, Jacob Burckhardt.

\section{II.1. Burckhardt unter Goethes Ägide}

Heinrich Wölfflin schrieb 1923 über seinen verstorbenen Lehrer und Freund:

Es konnte vorkommen, daß Jacob Burckhardt auf die Frage, was er als bestes Buch über Italien empfehle, kurzweg mit dem Hinweis auf Goethes italienische Reise antwortete. Wir Heutigen verstehen dieses Urteil kaum mehr. ${ }^{62}$

Uns heutigen erscheint Burckhardts Empfehlung hingegen eher als Gemeinplatz, als Banalität, wissen wir doch, daß die meisten Italienreisenden aus Burckhardts Bildungsschicht im 19. Jahrhundert mit der "Italienischen Reise « in der Tasche nach Arkadien zogen. Und es war eigentlich erst Burckhardt selbst, der diesen ehernen Lektürekanon des Bildungsbürgertums durchbrach, indem er ihm seine »Anleitung zum Genuss der Kunstwerke Italiens«, seinen »Cicerone« von 1855 an die Hand gab, der als eine Art Komplement der »Italienischen Reise « betrachtet werden kann. ${ }^{63}$ Hier lieferte er nun die konkreten Kunstbeschreibungen nach, die man beim Cicerone aus Weimar vermißt hatte. Der "Cicerone " wurde so das "Buch, das wie Goethes >Italienische Reise die Deutschen für Italien erzogen

${ }^{60}$ Jacob Burckhardt, Das Phäakenland Homers, op. cit., 176/77.

${ }^{61} \mathrm{Vgl}$. Jacob Burckhardts Gedicht "An Claude Lorrain «, in: id., Gedichte, Basel 1926, 99, V. 14.

${ }^{62}$ Heinrich Wölfflin, »Goethes Italienische Reise und der Begriff der klassischen Kunst «, in: Kunstchronik und Kunstmarkt 49/50 (1923), 817-820, hier 817.

${ }^{63}$ Es sei an dieser Stelle nochmals auf das von Meyer und Goethe geplante Italienwerk hingewiesen, das - wäre es ausgeführt worden - einen »Cicerone in nuce« hätte darstellen können. Vgl. auch Walther Rehm, Jacob Burckhardt und Goethe, in: id., Späte Studien, Bern/München 1964, 249-275, hier 263: „Der `Cicerone` von 1855 war seine, war Burckhardts >Italienische Reise «, 
hat ${ }^{64}$. Doch konnte Burckhardt wohl auch nur deshalb die würdige Nachfolge Goethes antreten, ${ }^{65}$ weil ihn so vieles mit dem großen Vorreisenden verband und weil er den Unsagbarkeitstopos vor dem Kunstwerk gerade mit Goethes klassizistischem ästhetischen Instrumentarium durchbrach. Zugleich fühlte er sich jedoch entgegen dem großen Vorbild Goethe in seinem »Cicerone « zur möglichsten Vollständigkeit der beschriebenen Kunstwerke verpflichtet: Dem Künstler Goethe sah man die subjektive Ausblendung und individuelle Selektion in der Kunstbeschreibung nach, während der Kunst-Historiker Burckhardt zur Systematik und zum lückenlosen Rapport gezwungen war. Dies verhinderte allerdings nicht, daß Burckhardt ebenso wie Goethe Opfer einer Rezeption wurde, die nur ganz bestimmte seiner Äußerungen für ihr Italienbild vereinnahmte.

Goethe war für Burckhardt von frühster Jugend an ein Vorbild, seine Freunde attestierten ihm ruhige Bildung, »goetheschen Objektivismus« und »künstlerische, goethesche Natur«, was durchaus nicht immer als Kompliment gemeint war. ${ }^{66}$ Als Muster sowohl in der Suche nach Beruhigung als auch im Gestus des Entsagens wurde Goethe für Burckhardt zum ruhenden Pol, den er auch »jenen ungeheuer interessanten, schmerzlich-skeptischen, geheimnisvollen Wesen à la Byron « entgegenstellte, zu denen »auch Heine eine Zeitlang gerne gehört hätte « ${ }^{67}$

Es war vor allem Italien, das diese beiden »Romani par Sehnsucht « verband, das Land, das ihre ästhetischen Maßstäbe prägte, das sie sich beide zeichnend und mit »malerischem Auge « (IR 299; 387) anschauend aneigneten und dessen Kunstschöpfungen sie dem »klosterbrudrisierenden, sternbaldisierenden Unwesen ${ }^{68}$

${ }^{64}$ Carl Neumann, Jacob Burckhardt, München 1927, 372.

${ }^{65}$ Es existieren drei mehr oder weniger ergiebige Untersuchungen zum Thema »Goethe und Burckhardt«: Auf wenigen Seiten bei Gottfried Bohnenblust, Goethe und die Schweiz, Frauenfeld 1932, 220ff., etwas ausführlicher, jedoch mit kaum mehr Tiefgang, Eugen Guglias Vortrag vor dem Wiener Goethe-Verein vom 10. 11. 1906 (1908 in der Chronik des Wiener Goethe-Vereins, Bd. XXI publiziert) und schließlich umfassend und ergiebig an Material, wenn auch sich weitestgehend auf explizite Goethe-Erwähnungen bei Burckhardt beschränkend: Walther Rehm, op.cit.

${ }^{66}$ Vgl. Walther Rehm, op. cit., $272 \mathrm{f}$.

${ }^{67}$ Brief an Albert Brenner vom 2. 12. 1855, in: Jacob Burckhardt, Briefe, hrsg. v. Max Burckhardt, Bd. III, Basel 1955, Nr. 296, 233; Burckhardt kritisiert dort Brenners Faust-Projekt, vor allem dessen »ultrabyronesken Faustcharakter« wohl vor der Positivschablone des Goetheschen »Faust «. In diesem Brief findet sich auch die treffende Beschreibung: „Ueberdieß ist es gar nicht Jedermanns Sache - wie es Goethes Sache war - sich poetisch zu häuten, sich von den Dingen durch das Kunstwerk zu befreien."

${ }^{68}$ Vgl. Über Polygnots Gemälde auf der rechten Seite der Lesche zu Delphi, Münchner Ausgabe, Bd. 6.2, hrsg. v. Victor Lange u.a., München 1988, 537: „Wem ist in diesen Phrasen [der Brüder Riepenhausen über griechische Kunst] die neukatholische Sentimentalität nicht bemerklich, das klosterbrudrisierende, sternbaldisierende Unwesen, von welchem der bildenden Kunst mehr Gefahr bevorsteht als von allen Wirklichkeit fodernden Kalibanen?«; vgl. auch die Invektiven in Goethes und Heinrich Meyers Gemeinschaftswerk »Neu-deutsche religios-patriotische Kunst«, Münchner Ausgabe, Bd. 11.2, hrsg. v. Johannes John u. a., München 1994, 319ff. Man vergleiche hierzu den Schluß von Burckhardts 1843 aus Kunststudien im Louvre hervorgegangenen Text »Über Murillo«, in: Die Kunst 
entgegensetzten. Burckhardt stand Goethe in der Stilisierung seiner Italienerlebnisse in nichts nach, ${ }^{69}$ was besonders deutlich anhand der frühen Reisen von 1837 / 38 illustriert werden kann; ebenso imitierte er in späteren Jahren den Kultur- und Technikpessimismus des alten Goethe. ${ }^{70}$ Den Spuren Goethescher Ästhetik im Werk des erklärten Nicht-Ästhetikers Burckhardt nachzugehen, erfordert wesentlich mehr Subtilität in der Analyse, obwohl bei vergleichender Lektüre der »Italienischen Reise « und des »Cicerone « mehrere Passagen auffallen, in denen Burckhardt seine Erläuterungen direkt über Goethe-Texte gearbeitet zu haben scheint ich werde dies abschließend am Beispiel Raffaels verdeutlichen. Burckhardt muß schon in jungen Jahren »seinen« Goethe sehr gut gekannt haben, fiel doch seine Jugend noch ins Ende der »Kunstperiode«, wuchs Burckhardt doch »noch im geistigen Klima der ausgehenden Goethezeit auf «: ${ }^{71}$ »Goethe war die gleichsam selbstverständliche Voraussetzung der geistigen Welt und des Schaffens dieses >humanen Spätlings « ${ }^{72}{ }^{72}$ Briefdatierungen auf Goethes Tod oder Geburtstag ${ }^{73}$, genaue Erinnerungen an die Todesmeldung des verehrten Dichters ${ }^{74}$ und die

der Betrachtung. Aufsätze und Vorträge zur bildenden Kunst, hrsg. v. Henning Ritter, Köln 1984, 120: „Gern möchte ich mit Overbeck noch zwei Worte vom Abfall reden! Ich würde ihm sagen, was ich für Abfall halte, nämlich nicht die redlichen, genialen Anstrengungen der Schulen von Bologna und Antwerpen, sondern seine höchsteigene Kunstpietisterei, die uns Raphael schlecht machen möchte, die sich nicht schämt, von den sauber erworbenen, durch die Riesenarbeit eines Rubens, van Dyck, Murillo, David, für uns gewonnenen Kunstmitteln faul und feige zu abstrahieren, um ohne all den Ballast von allgemeiner Kunstbildung, fester Zeichnung, wirklichem und wahrem Kolorit und dergleichen mit bloßer >Einfalt und Gottseligkeit ‘ auszukommen. Wer jetzt Fiesole nachahmt, kommt mir gerade vor wie einer, der die französische Revolution im Chronikenstil beschreiben wollte. Wozu hat denn unser Herrgott unserer Zeit diese Universalität gegeben, die ihr in allen Poren sitzt? «.

${ }^{69}$ Vgl. Walther Rehm, op. cit., 262: »In diesem Bereich [Italien] liegen denn auch die sichtbarsten, legitimsten und dauerndsten Berührungen mit Goethe und dessen Süderfahrung. Sie geben dem, was man bei Burckhardt Nachfolge Goethes nennen darf, den ebenso selbstverständlichen wie freien Zug innerer Zusammengehörigkeit und wahrer Sohnschaft. Die Einkehr Burckhardts in den Süden geschieht, von frühen romantischen Einflüssen abgesehen, überwiegend im Zeichen Goethes. «

${ }^{70}$ Vgl. z.B. einen der berühmten resümierenden Jahresabschlußbriefe an Friedrich von Preen vom 31. 12. 1877, Briefe, op. cit., Bd. VI, Basel 1966, Nr. 772, 228: „Göthe und die voreisenbahnliche Zeit! (...) Übrigens hat er schon in den 10er Jahren der damaligen aktiven Welt ihre 2 Hauptgelüste abgesehen und sagt es in irgend einem Brief an Zelter [nämlich im Brief vom 6. Juni 1825; Goethes Briefe, op. cit., Bd. IV, Nr. 1300, 146]: > Reichthum und Schnelligkeit - er wird an all die Extraposten gedacht haben die über das Pflaster von Weimar polterten.«

${ }^{71}$ Walther Rehm, op. cit., 249.

${ }^{72}$ Id., op. cit., 273.

${ }^{73}$ Burckhardt datiert seinen Brief vom 28. August 1838 an Johannes Riggenbach fälschlich wam Jahrestag von Göthe's Hinscheid«; Briefe, op. cit., Bd. I, Basel 1949, Nr. 22, 83.

${ }^{74}$ Brief an Friedrich v. Preen vom 31. 12. 1877, Briefe, op. cit., Bd. VI, Basel 1966, Nr. 772 , 228: "Göthe und die voreisenbahnliche Zeit! ja wohl, ich besinne mich noch wie seine Todesnachricht in den Zeitungen kam. (...) «. 
Bemerkung »Morgen sind es zehn Jahre seit Göthe starb, da geh ich zu Bettina ${ }^{75}$, mit der er seinen Kondolenzbesuch bei dem alternden Kinde in Berlin ankündigt, zeigen seine enge Verbundenheit mit Goethe, die bis zur Identifikation mit ihm reichte. Selbst von einer eigenen Faustdichtung ${ }^{76}$ und von frühen Liedkompositionen nach Goethe-Gedichten ${ }^{77}$ wissen wir. Burckhardts Goethe-Aneignung war keine punktuelle, bildungsbeflissene, sondern eine frühe und identifikatorische, die Goethe-Texte in hohem Maße »abgespeichert « haben muß, so daß sie bis ins hohe Alter reaktivierbar waren. Hierfür spricht nicht nur der von Burckhardt frei gehaltene Vortrag in einer Basler Studentenverbindung, dem Zofingerverein, dessen Protokollakten für die Sitzung vom 23. August 1838 vermerken: "Zum Schlusse gab Jak. Burckhardt in freiem Vortrage interessante Notizen über das Verhältnis Goethes zur Schweiz, größtentheils aus göthischen Schriften zusammengestellt. Veranlaßung dazu gab ihm der herannahende Geburtstag Göthe's (28. August) «. ${ }^{78}$ Auch seine Fähigkeit, mit leichten Ungenauigkeiten selbst abgelegene Stellen aus Goethes Korrespondenz und aus den Gesprächen frei aus dem Gedächtnis zu zitieren ${ }^{79}$ und manche an Goethesche Sentenzen erinnernde Äußerung in seinen Briefen ${ }^{80}$ zeigen seine Abhängigkeit von dem großen Vorbild. Burckhardt hat das beschriebene Phänomen selbst bei seiner letzten Erwähnung Goethes in einem Brief aus dem Jahr 1890 auf die Formel gebracht, ein Brief, in dem er dem jüngeren Wilhelm Schäfer eine Lektion über die Kunst, Italien zu bereisen, erteilte:

Täuschen wir uns nicht. Das Verhältniß der gebildeten Deutschen zu Italien ist ein ganz anderes geworden als es vor einigen Jahrzehnten war, da relativ Wenige aber zu langen und mehrmaligen Aufenthalten das Land besuchten und da die Anschauung Italiens als eine geistige Ergänzung des deutschen Wesens galt. Ich bin noch in jenen Zeiten und unter der Einwirkung Göthe's jung gewesen, und Sie, H. Herr, sind nun aus einer jüngern Generation einer der sehr Wenigen, welche Italien sich auf ähnliche Weise haben aneignen könnnen. ${ }^{81}$

${ }^{75}$ Brief an Gottfried Kinkel vom 21. 3. 1842, Briefe, op. cit., Bd. I, Basel 1949, Nr. 59, 198.

${ }^{76} \mathrm{Vgl}$. Walther Rehm, op. cit., 253.

${ }^{77}$ Vgl. Brief an Johannes Riggenbach vom 28. 8. 1838, loc. cit.: »Am Jahrestag von Göthe's Hinscheid füge ich meinem Brief noch eine Composition von des Wanderers Nachtlied für dich bei.«

${ }^{78}$ Staatsarchiv Basel-Stadt, PA 412, E 7, 10d: Zentralarchiv des Zofingervereins, Sektion Basel, Protokolle der Basler Sektion des Zofinger Vereins, fol. 1161.

${ }^{79}$ Vgl. z. B. Brief an Max Alioth vom 22, 8. 1880, Briefe, op. cit., Bd. VII, Basel 1969 , Nr. 887, 176 oder den Brief an Friedrich v. Preen vom 20. 7. 1882, an den immerwährenden Freund der späten Jahre also, dem gegenüber Burckhardt mit besonderer Vorliebe Goethe evoziert: Briefe, op. cit., Bd. VIII, Basel 1974, Nr. 969, 46.

${ }^{80}$ Als nur ein Beispiel unter unzähligen sei der Brief vom 30. November 1843 an Eduard Schauenburg zitiert, Briefe, op. cit., Bd. II, Basel 1952, Nr. 99, 56: "Jetzt sammeln sich in mir die Anschauungen von den Reisen und den Menschen und strahlen und funkeln schön gegeneinander und assimilieren sich zu Bildern und Geschichten.«

${ }^{81}$ Briefe, op. cit., Bd. IX, Basel 1980, Nr. 1322, 266. 


\section{II.2. »Unter der Einwirkung Göthe's jung gewesen « - Die Goethe-Stilisierung der frühen Reisen}

Mitte Juli 1837 brach Jacob Burckhardt von Basel aus zu einer Wanderung durch die Schweiz zusammen mit seinen Freunden Aloys Biedermann, Theodor Meyer, Johannes Riggenbach und seinem Cousin Johann Jakob Oeri auf. ${ }^{82} \mathrm{Ob}$ er zu diesem Zeitpunkt schon wußte, daß dies zugleich seine erste Italienreise werden sollte, wissen wir nicht. Jedoch verdanken wir dieser illegalen - da reisepaßlosen Grenzgängerei über die Alpen einen zwischen literarischer Fiktion im Stile Goethes und apodemisch angehauchtem Reisebericht schwankenden Text mit dem Titel »Fünf Tage jenseits der Alpen ${ }^{83}$, den Biedermann zusammen mit Burckhardt verfaßte. ${ }^{84}$ Dieser, wie die meisten frühen Italientexte und Briefe Burckhardts, trägt zugleich noch einen gewissen, später eher unterdrückten Heineschen Zug, so z.B. in der Evokation des sehr klassischen Hexensabbats in der Tribuna der Uffizien, wo sich um Mitternacht die antiken Statuen verlebendigen (133ff.).

Die Beschreibung der fünf gestohlenen Tage in Italien ist voll der goetheschen Reminiszenzen, ja es scheint, als hätten die Schweizer Wanderer versucht, einzelne Italienerlebnisse Goethes nachzustellen, zum Teil sogar zu überbieten. Das gesamte Arsenal der "Italienischen Reise « ist hier versammelt - der unerwartete, fluchtartige Aufbruch als zweites »Karlsbad « (16f.), (Binnen)seestürme (100), falsche Warnungen vor angeblich verrufenen Gasthäusern (46), hübsche Wirtstöchter (23f.), verrückte Geistliche (99f.), das »klassische«, verheißene Land $(85 ; 107)$, der berühmte Gutenachtgruß »felicissima notte ( 27$)$, von blühenden Zitronenbäumen und glühenden Blutorangen ganz zu schweigen $(16,33)$. Auch Mignon ${ }^{85}$, »das wundervolle Kind«, geistert durch alle frühen Italientexte Burckhardts $(83)^{86}$, und Marmorbilder sehen ihn ebenfalls häufiger an $(62,134)$. Bezeichnend ist die folgende Äußerung Burckhardts über Mignon (83): „Überhaupt wird man in Italien der Beziehungen und Erinnerungen an das wundervolle Kind nicht los; es gewinnt nach und nach in der Seele des Reisenden eine vollkommene historische Wirklichkeit.« Das heißt aber eben, daß man »der Beziehungen und Erinnerungen « an Goethe nicht los wird, daß es sein Italien ist, das sich auf Burckhardts

${ }^{82} \mathrm{Zu}$ den $»$ Realien der Reise vgl. Werner Kaegi, Jacob Burckhardt. Eine Biographie, 7 Bde., Basel 1947-1982, Bd. I (1947), 515ff.

${ }^{83}$ Zuerst erschienen im Wanderer in der Schweiz 4 (1838), hier zitiert nach dem Wiederabdruck in: Jacob Burckhardt, Reisebilder aus dem Süden, hrsg. v. Werner von der Schulenburg, Heidelberg 1928, 15-55.

${ }^{84}$ Von Burckhardt stammt laut Werner Kaegi (op. cit., 516) nur die Schilderung des 1. August, es ist jedoch anzunehmen, daß er redaktionell auch Einfluß auf den Text von Biedermann genommen hat.

${ }^{85} \mathrm{Vgl}$. Marianello Marianelli, op. cit., 119, der (Baioni zitierend) behauptet, Mignon trage wirgendwie schon das Gesetz der Urpflanze in sich «, was dann doch wohl eher - will man diese Übertragung unbedingt leisten - auf Lady Hamilton zutrifft.

${ }^{86} \mathrm{Vgl}$. z. B. die ebenfalls bei von der Schulenburg, op. cit., $56 \mathrm{ff}$. abgedruckten $»$ Bilder aus Italien $«$ von 1839. 
Reisen verlebendigt und ihm zeitlos und historisch zugleich omnipräsent entgegentritt.

Den Höhepunkt der Goethe-Überbietung bildet jedoch die Beschreibung in den »Fünf Tagen jenseits der Alpen«, in der »Karl«, alias Jacob Burckhardt, in einem Wirtshaus in Andermatt versucht, seine Freunde zum Schritt über die Grenze zu überreden. Diese Passage, die im folgenden ausführlich zitiert werden soll, ist ganz eindeutig über Goethes Schilderung seiner unterlassenen Grenzüberschreitung im Juni 1775 aus dem 19. Buch von »Dichtung und Wahrheit« gearbeitet, wo es heißt:

Früh aufgestanden, befand ich mich bald zwar unter freiem Himmel jedoch in engen von hohen Gebirgskuppen umschlossenen Räumen. Ich hatte mich an den Fußpfad, der nach Italien hinunterging, niedergelassen und zeichnete, nach Art der Dilettanten, was nicht zu zeichnen war und was noch weniger ein Bild geben konnte: die nächsten Gebirgskuppen, deren Seiten der herabschmelzende Schnee mit weißen Furchen und schwarzen Rükken sehen ließ; indessen ist mir durch diese fruchtlose Bemühung jenes Bild im Gedächtnis unauslöschlich geblieben. Mein Gefährte trat mutig zu mir und begann: »Was sagst Du zu der Erzählung unsres geistlichen Wirts von gestern Abend? Hast Du nicht, wie ich, Lust bekommen, Dich von diesem Drachengipfel hinab in jene entzückenden Gegenden zu begeben? Die Wanderung durch diese Schluchten hinab muß herrlich sein und mühelos, und wann sichs dann bei Bellinzona öffnen mag, was würde das für eine Lust sein! Die Inseln des großen Sees sind mir durch die Worte des Paters wieder lebendig in die Seele getreten. Man hat seit Keislers Reisen so viel davon gehört und gesehen, daß ich der Versuchung nicht widerstehen kann. Ist Dir's nicht auch so? fuhr er fort; Du sitzest gerade am rechten Fleck, schon einmal stand ich hier und hatte nicht den Mut hinabzuspringen. Geh voran ohne weiteres, in Airolo wartest Du auf mich (...). «So ganz aus dem Stegreife ein solches Unternehmen, will mir doch nicht gefallen, antwortete ich. - „Was soll da viel Bedenken! rief jener, Geld haben wir genug nach Mayland zu kommen, Kredit wird sich finden (...).« Er ward noch dringender. Geh! sagte ich, mach' alles zum Abschied fertig, entschließen wollen wir uns alsdann.

Doch die Entscheidung fällt bekanntlich gegen das Fremde für das Bekannte, Heimische, Geliebte:

Schnell stand ich auf, damit ich von der schroffen Stelle wegkäme und der mit dem refftragenden Boten heranstürmende Freund mich in den Abgrund nicht mit fortrisse. Auch ich begrüßte den frommen Pater und wendete mich, ohne ein Wort zu verlieren, dem Pfade $\mathrm{zu}$, woher wir gekommen waren. ${ }^{87}$

Bei Burckhardt und seinen Freunden spielt sich die entsprechende Szene wie folgt ab (16f.):

Wir saßen da, ohne an etwas weiteres zu denken, da hub Karl mit bedeutungsvoller Miene an: Ich hätte euch was vorzubringen, ihr dürft mich aber nicht unterbrechen - wir standen in gespannter Erwartung - seht, fuhr er fort den Finger auf der Karte, seht welch kleine Strecke es noch bis Italien ist, nach Italien, wo die Zitronen blühn, nach Italien, nach dem ihr euch alle so sehnt. Laßt das Oberland fahren und fasset einen raschen Entschluß! Dann zeigte er auf der Karte einen Plan, der wenig über die Schweiz hinausging,

${ }^{87}$ Aus meinem Leben. Dichtung und Wahrheit, Münchner Ausgabe, Bd. 16, hrsg. v. Peter Sprengel, München 1985, 791f.. 
aber es war doch Italien. Einen Augenblick herrschte Schweigen, einige Bedenklichkeiten Heinrichs aber wurden beseitigt, dann brachen wir in lauten Jubel aus: dahin, dahin, laßt uns, ihr Freunde, ziehn. Und wir jubelten zum Hospiz hinauf; nur einer schritt gesenkten Blicks voran, machte bedenkliche Mienen und schüttelte das Haupt; denn er fühlte keinen Trieb in sich nach Italien. Droben im Hospiz trafen wir einige Russen an, die, eben aus Italien gekommen, im Begriff standen, den Fieudo zu besteigen und dann die übrige Schweiz zu bereisen. Die erzählten uns da, wie herrlich die Aussicht auf dem Schloß zu Bellenz, wie reizend der Lago Maggiore, und wie wunderschön die Borromäischen Inseln. Das rührte denn auch das Herz unsers Freundes, daß es einen Aufschwung nahm, aber leider bald an den Nafenen hängen blieb; denn diesen $\mathrm{Pa}$ hatten wir auf dem Heimweg vor (...). Nein, nein, rief er, so mag ich mein junges Leben nicht in die Schanze schlagen; (...) So schieden wir und er, wie weiland Goethe getan, schaute nieder von der Höhe des Gotthards, dahin wo man die schöne Sprache redet und kehrte dann zurück zu den Fleischtöpfen und Kaffeekannen der Heimat.

Überbietung Goethes also in jugendlich-romantischem Überschwang: Zwar vollzieht einer der Freunde, der zaudernde Johann Jakob Oeri, den berühmten »Scheideblick « Goethes »nach Italien vom Gotthard ${ }^{88}$ nach und kehrt um, die übrigen vier jedoch schlagen Goethes Bedenken in den Wind: »Uns aber trug die Freude auf ihren Flügeln hinunter nach Airolo.« (17).

\section{II.3. Burckhardts »Goethesche Ästhetik «}

Den Abschluß dieser Betrachtungen sollen einige streiflichtartige Bemerkungen zu Burckhardts »Goethe-Imitatio« im Bereich seines Kunsturteils bilden. ${ }^{89}$

Es ist erstaunlich, in welch hohem Maße eigentlich die gesamte Goethesche »römische« Ästhetik in Burckhardts Schriften zur Kunst wiederzufinden ist, und wie diese Adaptation sich in seinen eigenen Bildbeschreibungen wiederspiegelt. An vielen Stellen sind Goethes Ansätze weiterentwickelt, spielen auch noch andere Vorbilder wie Wilhelm v. Humboldt und Karl Philipp Moritz eine wichtige Rolle, die es Burckhardt z. B. ermöglichten, die bei Goethe negativ besetzte Einbildungskraft als ergänzende, künstlerisch nachschaffende Kraft des Kunstbetrachters zu nobilitieren. ${ }^{90}$ Doch trotz aller Modifikationen bleibt Goethes Kunsttheo-

${ }^{88}$ Vgl. hierzu: Corpus der Goethe-Zeichnungen, 7 Bde., bearb. v. Gerhard Femmel, Leipzig 1958-1973, Bd. I (1958), Abb. 120, Kommentar S. 52, (Inv.Nr. 94). Die Zeichnung trägt Goethes eigenhändigen Bleistiftvermerk: "Scheide Blick nach Italien vom Gotthard d. 22. Juni 1775 «.

${ }^{89}$ Die Verfasserin hofft, hiervon eine detailliertere Analyse in ihrer in Arbeit befindlichen Dissertation »Eine Aufgabe zum Geniessen. Jacob Burckhardts >Cicerone« geben zu können.

${ }^{90}$ Die »restaurierende Kraft« der Phantasie ermöglicht es auch, die von Goethe noch extrem empfundene Irritation durch antike »Trümmer« zu überwinden, indem man in der Einbildungskraft die Ruinen zum ursprünglichen unversehrten Ganzen ergänzt; was der Historiker Burckhardt als Chance sieht - die Vielschichtigkeit Roms nämlich erscheint Goethe nur als Hindernis: „Doch auch in Rom ist zu wenig für den gesorgt, dem es Ernst ist ins Ganze zu studieren. Er muß alles aus unendlichen, obgleich überreichen 
rie überall als Substrat bei Burckhardt erkennbar: Sei es im Ideal des organischen Kunstwerkes, in dem alle Einzelteile zur Harmonie des Ganzen beitragen, zum »organischen Ganzen« (Cic. 3), das dem Betrachter »einen großen künstlerischen Genuß« (Cic. 25) vermittelt, sei es die Vorstellung von einer metamorphotischen Kunstentwicklung, die es Burckhardt ermöglicht, organische Stile (den griechischen und den gotischen) von abgeleiteten (dem römischen und dem Renaissancestil) zu unterscheiden ${ }^{91}$ und eine Stufenfolge von primären, sekundären und tertiären Künstlern aufzustellen. ${ }^{92}$ Goethes Vorstellung einer verdeckten oder »verheimlichten « Symmetrie im gelungenen Kunstwerk ${ }^{93}$ findet sich in Burckhardts "Äquivalentenlehre « in den "Erinnerungen aus Rubens « wieder, wobei diese »Äquivalente im Bild sowohl optische als auch moralische Werte der dargestellten Figuren sein können, die sich gegenseitig aufwiegen. ${ }^{94}$ Die »Äquivalente im Bild sind ein Mittel der Beruhigung: »In momentan sehr mächtigen Kompositionen des Rubens genießt der Beschauer, zunächst unbewußt, neben der stärksten dramatischen Bewegung, eine geheimnisvolle optische Beruhigung, bis er inne wird, daß die einzelnen Elemente jener nach Kräften verhehlten Symmetrie, ja einer mathematischen Figur untertan sind. ${ }^{95}$

Geradezu leitmotivisch und wortgleich taucht bei Burckhardt wie bei Goethe die Kategorie »gut gedacht « zur Beurteilung von Bildern auf: Die aus der Kunstliteratur der Renaissance hinlänglich bekannte »invenzione« wird hier zur leitenden Kategorie der Bildbeurteilung erhoben; überzeugt die von der Ausführung

Trümmern zusammenstoppeln.« (IR 194f.); zum Phantasiebegriff vgl. u. a. Jacob Burckhardt, Aesthetik der bildenden Kunst, hrsg. v. Irmgard Siebert, Darmstadt 1992, $89 \mathrm{ff}$. (»Über die ergänzende Kraft der Phantasie«).

${ }^{91}$ Jacob Burckhardt, Der Cicerone, op. cit., 284: »In Zeiten eines organischen Stiles, wie der griechische und der nordisch-gothische waren, erledigt sich nun die Sache von selbst; eine und dieselbe Triebkraft bringt die Formen und Proportionen untrennbar vereinigt hervor. Hier [i.e. beim Renaissancestil] handelt es sich um einen sekundären Stil, der seine Gedanken freiwillig [i.e. nicht notwendig] in fremder Sprache ausdrückt.«

${ }^{92}$ Jacob Burckhardt, Über das Studium der Geschichte, hrsg. v. Peter Ganz, München 1982, 384.

${ }^{93} \mathrm{Vgl}$. hierzu v. a. das Kapitel II.1 "Bedeutende Falten. Goethes Beschreibung von Marcantonio Raimondis Apostelzyklus«, in: Ernst Osterkamp, op. cit., 54-71; vgl. IR 442: „Eine Anordnung deren Symmetrie aus dem gegebenen hervorgeht und welche wieder durch die Erfordernisse des Darzustellenden nicht sowohl verborgen als belebt wird; (...). «

${ }^{94} \mathrm{Vgl}$. Jacob Burckhardt, Erinnerungen aus Rubens, op. cit., 430.

95 Op. cit., 433; vgl. auch ibid. 430: "Diese Symmetrie aber, bei ihrer Herkunft im Ganzen, mußte dem Auge nach Kräften entzogen, im Einzelnen aufgehoben werden, und so gewiß nun auch dieses schon ein anerkanntes Lebensgesetz der Malerei der Hochblüte [i.e. Raffaels] gewesen war, so kann doch erst Rubens als der vollständige Herr auf diesem geweihten Gebiete gelten. Denn nur bei ihm verbindet sich die reichlichste symmetrische Handhabung des Verschiedenen, aber Ähnlich-Wertigen, der Äquivalente, im Bild mit dem lebendigsten, selbst mit dem allerheftigsten Hergang zu jenen siegreichen Wirkungen, welche den äußern Blick und den innern Sinn zugleich bezaubern. Die Rosse seines Sonnenwagens sind feurige Tiere, aber sie dürfen nicht mit ihm durchgehen.« 
ablösbar zu betrachtende Bildidee, so ist hiermit - eventuell auch gegen Mängel in der malerischen Ausführung - schon ein positives Urteil im Sinne einer möglichen Bewertung "gut gedacht, aber ...« über das zur Diskussion stehende Kunstwerk ausgesprochen. Burckhardt geht im Gefolge der Humboldtschen »Ideenlehre noch einen Schritt weiter und beschreibt in den sogenannten »Weltgeschichtlichen Betrachtungen « die Aufgabe des Künstlers wie folgt: »Künstler, Dichter und Philosophen haben zweierlei Function: den innern Gehalt der Zeit und Welt ideal zur Anschauung zu bringen und: ihn als unvergängliche Kunde auf die Nachwelt zu überliefern. ${ }^{96}$

Für Goethe wie für Burckhardt verfügt die Kunst über eine sittlich-erhebende Komponente, das Kunstwerk hat »moralische Verweiskraft «. ${ }^{97}$ So schreibt Goethe am 20. Dezember 1786 aus Rom: »Gebe der Himmel, daß bei meiner Rückkehr auch die moralischen Folgen an mir zu fühlen sein möchten, die mir das Leben in einer weitern Welt gebracht hat. Ja es ist zugleich mit dem Kunstsinn der sittliche, welcher große Erneuerung leidet.« (IR 177), und Burckhardt echot in einem Brief an Albert Brenner vom 17. Oktober 1855: „Die beständige Anschauung des Schönen und Großen soll unseren ganzen Geist liebevoll und glücklich machen. Auch unser Ehrgeiz soll sich dadurch vom Stadium der Eitelkeit zur Ruhmbegier erheben. ${ }^{98}$ Derjenige Künstler, der für beide diese Elevation zum Sittlichen am vollkommensten repräsentiert - und hier befinden sie sich natürlich wiederum in einer langen Tradition der Kunstliteratur - ist »Raffaello divino«, der gottbegnadete Jüngling, von dem Burckhardt im »Cicerone « (884) schreibt: »Die höchste persönliche Eigenschaft Raffaels war (...) nicht ästhetischer, sondern sittlicher Art: nämlich die große Ehrlichkeit und der starke Wille, womit er in jedem Augenblick nach demjenigen Schönen rang, welches er eben jetzt als das höchste Schöne vor sich sah.« Raffael, der für Goethe den Schlußstein der quattrocentesken Kunstentwicklung repräsentierte (IR 118) und zu dessen »Schädelreliquie « er wallfahrtet (IR 645), vereint alle klassischen Tugenden in sich: Er ist natürlich und göttlich zugleich, er ist »normal« und »gesund«, er läßt dieselbe Ökonomie wie die Natur walten, um höchsten Kunstgenuß hervorzubringen, seine Bilder zeigen den Reiz der geschlossenen Komposition, seine Madonnen bedürfen des göttlichen Glanzes nicht, sie sind als Frauengestalten schon himmlisch. So verwundert es nicht, daß Burckhardt bei seinen Raffael-Elogen zum Teil wortgleich an Goethes Beschreibungen vom Zweiten Römischen Aufenthalt anknüpft. Exemplarisch sei hier auf Goethes und Burckhardts Äußerungen zu Raffaels Transfiguration und zu den Sibyllen in S. Maria della Pace hingewiesen. Über das »herrliche Bild der

${ }^{96}$ Über das Studium der Geschichte, op. cit., 381; vgl. auch ebenda, 279: „Aus Welt, Zeit und Natur sammeln Kunst und Poesie allgültige, allverständliche Bilder, die das einzige irdisch Bleibende sind, eine zweite, ideale Schöpfung, der bestimmten einzelnen Zeitlichkeit enthoben, irdisch-unsterblich, eine Sprache für alle Nationen.«

${ }^{97}$ Andreas Beyer, Bestimmung und Selbstbestimmung, op. cit., 664.

${ }^{98}$ Briefe, op. cit., Bd. III, Basel 1955, Nr. 293, 226. 
Transfiguration « schreibt Goethe im Dezember 1787, als er mit seinen Freunden einen zweiten römischen Raffael-Parcours durchläuft:

Da war denn des Redens viel; der stillere Teil jedoch ärgerte sich den alten Tadel von doppelter Handlung wiederholt zu sehen. (...) Wundersam bleibt es indes immer, daß man an der großen Einheit einer solchen Konzeption jemals hat mäkeln dürfen. In Abwesenheit des Herren stellen trostlose Eltern einen besessenen Knaben den Jüngern des Heiligen dar; sie mögen schon Versuche gemacht haben den Geist zu bannen; man hat sogar ein Buch aufgeschlagen um zu forschen ob nicht etwa eine überlieferte Formel gegen dieses Übel wirksam könne gefunden werden; aber vergebens. In diesem Augenblick erscheint der einzig Kräftige und zwar verklärt, anerkannt von seinen großen Vorfahren, eilig deutet man hinauf nach solcher Vision, als der einzigen Quelle des Heils. Wie will man nun das Obere und Untere trennen? beides ist eins: unten das Leidende, Bedürftige, oben das Wirksame, Hülfreiche, beides auf einander sich beziehend, ineinander einwirkend. Läßt sich denn, um den Sinn auf eine andere Weise auszusprechen, ein ideeller Bezug aufs Wirkliche von diesem lostrennen? Die Gleichgesinnten bestärkten sich auch diesmal in ihrer Überzeugung; Rafael, sagten sie zu einander, zeichnete sich eben durch die Richtigkeit des Denkens aus, und der Gottbegabte Mann, den man eben hieran durchaus erkennt, soll in der Blüte seines Lebens falsch gedacht, falsch gehandelt haben? Nein! er hat, wie die Natur, jederzeit Recht, und gerade da am gründlichsten wo wir sie am wenigsten begreifen. (IR 540f.)

Die Kunsttheorie des 18. Jahrhunderts - z. B. Richardson, Falconet und v. Ramdohr - hatte häufig an Raffaels »Transfiguration« das Auseinanderfallen des Bildes in zwei getrennte Sphären - eine irdische und eine transzendente - kritisiert. Burckhardt unterstützt Goethes Argumentation, indem er noch pointierter den Ausgleich des »dramatischen Gegensatzes« (Cic. 856) von Oben und Unten herausarbeitet. Gleichzeitig argumentiert er jedoch nicht so überzeugend wie Goethe, wieso »das Gemälde ein Ganzes« bilde, sondern liefert nur einen Zirkelschluß auf inhaltlicher Ebene: Die Szenen seien genialisch durch Raffael zusammengebunden worden - »welch ein Augenblick mochte das sein, da dem Künstler der Gedanke an eine Verbindung beider Szenen aufging « (Cic. 858), »die nur im Geiste des Beschauers « (Cic. 856) und des Künstlers, nicht jedoch im zugrundeliegenden Bibeltext existiere, so lautet die Voraussetzung für die Größe dieses Kunstwerkes, die zugleich auch als Begründung herhalten muß, wenn Burckhardt fortfährt: »Und doch wäre die eine ohne die andre unvollständig; es genügt, die Hand vor die obere oder vor die untere zu halten, um zu erkennen, wie sehr das Gemälde ein Ganzes bildet.« Quod erat demonstrandum! (Cic. 856). Man fragt sich, wieviele Generationen deutscher Oberlehrer mit dem »Cicerone « in der Hand dieses Experiment mit großer Beflissenheit nachvollzogen haben mögen.

Noch deutlicher wird die Filiation Goethe-Burckhardt bei der Beschreibung der Sibyllengestalten über dem Bogen der Cappella Chigi in S. Maria della Pace. Anhand dieser Beschreibung unterstreicht Goethe die Fähigkeit des hochbegabten Künstlers, gerade bei den ungünstigsten räumlichen Gegebenheiten die wunderbarsten Lösungen zu finden, ein Urteil, das Burckhardt ebenfalls als Hauptargument für die Genialität Raffaels benutzt. In der »Italienischen Reise « heißt es: 
Rafael war niemals von dem Raume geniert den ihn die Architektur darbot, vielmehr gehört zu der Großheit und Eleganz seines Genies, daß er jeden Raum auf das zierlichste zu füllen und zu schmücken wußte, wie er augenfällig in der Farnesine dargetan hat. Selbst die herrlichen Bilder der Messe von Bolsena, der Befreiung des gefangenen Petrus, des Parnasses, wären ohne die wunderliche Beschränkung des Raumes nicht so unschätzbar geistreich zu denken. Eben so ist auch hier in den Sibyllen die verheimlichte Symmetrie, worauf bei der Komposition alles ankommt, auf eine höchst geniale Weise obwaltend; denn wie in dem Organismus der Natur so tut sich auch in der Kunst innerhalb der genausten Schranke die Vollkommenheit der Lebensäußerung kund. (IR 542)

Und Burckhardt schreibt im »Cicerone«:

Raffael dagegen drückte gerade in der Verbindung der Sibyllen mit den Engeln den schönsten Enthusiasmus des Verkündens und Erkennens aus. Man bemerkt lange nicht, daß die Engel von kleinerm Maßstabe sind; wie etwa die Griechen den Herold kleiner als den Helden bilden mochten. Die Anordnung im Raum, die durchgehende und so schön aufgehobene Symmetrie, die Bildung der Formen und Charaktere verleihen diesem Werk eine Stelle unter den allergrößten Leistungen Raffaels (...). (Cic. 880)

Anläßlich der Beschreibung der »Messe von Bolsena« fährt er fort:

Die Anordnung neben und über dem nicht einmal in der Mitte der Wand stehenden Fenster scheint für Raffael ein wahres Spiel gewesen zu sein; eben aus der Unregelmäßigkeit entwickeln sich für ihn die schönsten Motive wie von selbst. Bei genauerer Betrachtung wird man aber von dieser Ansicht abgehen und glauben, daß viel Mühe und Nachsinnen dabei war. (Cic. 870)

\section{Und schließlich die Farnesina-Fresken:}

Raum und Format der Zwickel waren für Geschichten von mehreren Figuren scheinbar so ungeeignet als möglich; Raffael aber entwickelte gerade daraus (wie aus der Wandform bei der Messe von Bolsena, der Befreiung Petri, den Sibyllen) lauter Elemente eigentümlicher Schönheit. (Cic. 882)

Gleichklang im Lob des göttlichen Jünglings also, dem keine ästhetische Aufgabe zu schwer, keine sittliche Anfechtung unbestehbar war. Jedoch ist dieser Raffael Goethes und Burckhardts trotz aller verklärenden Tendenzen nicht der pflaumenweiche Nazarenerjüngling, der »allenfalls mit der Jungfrau Maria verkehrte ${ }^{99}$ und dessen Madonnen den Betrachter in höchste religiöse Verklärung versetzen. Es ist vielmehr der Künstler der neueren Zeit, dem es als einzigem in höchster Vollkommenheit gelungen ist, die griechisch-antiken Gestaltprinzipien wiederzuerwecken. Durch seine schon von Winckelmann bewunderte »Gräcität « wird er zum Vollender der Kunstentwicklung: ${ }^{100}$ Die Frömmelei wird durch die Natürlichkeit substituiert, in der höchsten Kunst zeigt sich die erhöhte Natur. Burckhardt legt Raffael eine weitere genuin griechische Fähigkeit bei, die er bei Homer, bei

${ }^{99}$ Ernst Osterkamp, op. cit., 70.

${ }^{100} \mathrm{Vgl}$. IR 124, wo Goethe eine Hl. Agathe lobt, die er fälschlich Raffael zuschreibt: „Der Künstler hat ihr eine gesunde, sichere Jungfräulichkeit gegeben, doch ohne Kälte und Rohheit. Ich habe mir die Gestalt wohl gemerkt, und werde ihr im Geist meine Iphigenie vorlesen, und meine Heldin nichts sagen lassen, was diese Heilige nicht aussprechen möchte «; oder IR 155f.: „Die Logen von Raphael und die großen Gemälde der Schule 
Claude Lorrain und bei Rubens ebenso entwickelt findet wie bei dem verehrten Dichter des zweiten Teiles des »Faust «, nämlich die »lebensfrische Versinnlichung des Mythos $« .{ }^{101}$ Wenn er in einem Brief an Albert Brenner vom 11. November 1855 schreibt: »Das Mythische [in »Faust $\mathrm{II} «]$ ist mit einer gewissen großarthigen Anmuth behandelt, als sähe man Rafael die Geschichten der Psyche malen. ${ }^{102}$, so wird ihm Goethe selbst zu einer raffaelischen Gestalt. Es bedarf für Burckhardt solcher Gestalten, die ihm das »ruhige Glück der Seele « vermitteln, »welches er in Rom genossen « hat ${ }^{103}$ - wie es bekenntnishaft am Schluß des »Cicerone « (999)

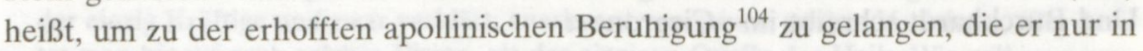
Italien auf Goethes Spuren finden konnte.

von Athen etc. hab' ich nur erst einmal gesehen, und da ist's, als wenn man den Homer aus einer zum Teil verloschenen, beschädigten Handschrift herausstudieren sollte.«; vgl. auch Jacob Burckhardt, Der Cicerone, op. cit., 884.

${ }^{101}$ Brief an Paul Heyse vom 6. Mai 1855, Briefe, op. cit., Bd. III, Basel 1955, Nr. 288, 216.

${ }^{102}$ Briefe, loc. cit., Nr. 294, 229.

${ }^{103} \mathrm{Vgl}$. die berühmte Parallelstelle bei Goethe in den Gesprächen mit Eckermann, 9. 10. 1828: »Ja ich kann sagen, daß ich nur in Rom empfunden habe, was eigentlich ein Mensch sei. Zu dieser Höhe, zu diesem Glück der Empfindung bin ich später nie wieder gekommen; ich bin, mit meinem Zustand in Rom verglichen, eigentlich nachher nie wieder froh geworden. «

${ }^{104}$ In diesem Zusammenhang sei nochmals kontrastiv auf den »dionysischen « Heinse verwiesen, dessen Tagebuchbeschreibung der »Madonna di Foligno « vom 13. 7. 1783 sich deutlich von den Anleitungen zum Genuß des "Cicerone « unterscheidet: "Es ist der Mühe werth, deßwegen allein nach Fuligno zu reisen. Die Madonna, der Heilige Francesco, der Heilige Hieronymus welche Figuren, welche Charakter! wie ist alles so rein bis aufs Haar bestimt, ächte griechische klaßische Arbeit. Im Kopf der Madonna ist alles himmlische vereinigt, was bey den schönsten weiblichen welschen Köpfen hier und da angetroffen wird. Wie klar die Stirn, wie reizend das lichte Kastanien Haar nach den Ohren weggelegt, der bräunliche Schleyer wie sanft und lieblich, in den hold hernieder blickenden Augen welche Güte! wie schön die großen Augenlider, die vollen jugendlichen Wangen mit Schaamröthe überzogen, wie jungfräulich, wie süß der völlige Mund und das zarte Kinn, und die Nase wie unschuldig herein, welch ein schönes Oval und wie reizend auf der rechten Seite herum bis auf den Hals in Schatten gehalten. Wie reizend schwellen die Brüste unter dem rothen sittsamen Gewand hervor (...).«; Wilhelm Heinse, Sämmtliche Werke, op. cit., Bd. VII, Leipzig 1909 (ND München 1977), 115f. Dies scheint eher die Beschreibung eines geliebten Mädchens zu sein als einer Raffael-Madonna! Dagegen Burckhardt (Der Cicerone, op. cit., 852): «Als Mutter Gottes mit Heiligen erreicht dies Bild gerade alles das, was die Florentiner gern erreicht hätten: ein gewaltig erhöhtes geistiges Leben in den Heiligen; der innigste Bezug zum gläubigen Beschauer sowohl als zur Jungfrau; letztere übrigens nur als ideale Mutter, nicht als Königin des Himmels $(\ldots) \propto$. 